\title{
CD4 + T cells are found within endemic Burkitt lymphoma and modulate Burkitt lymphoma precursor cell viability and expression of pathogenically relevant Epstein-Barr virus genes
}

\author{
Semjon Sidorov ${ }^{1}$ (1) $\cdot$ Lara Fux $^{1} \cdot$ Katja Steiner $^{1} \cdot$ Samyo Bounlom $^{1} \cdot$ Sabrina Traxel $^{1}$ (1) $\cdot$ Tarik Azzi $^{1}$ (1) . \\ Arbeneshe Berisha $^{3,4}$. Christoph Berger ${ }^{1}$ D $\cdot$ Michele Bernasconi $^{1,5,6}$ (D) Felix K. Niggli ${ }^{1}$ (D) Yvonne Perner $^{2}$ (D) . \\ Sugeshnee Pather ${ }^{2}$ (D) $\cdot$ Werner Kempf $^{3,4}$ (DD $\cdot$ David Nadal $^{1}$ (D) Simone Bürgler ${ }^{1}$ iD
}

Received: 9 January 2021 / Accepted: 8 September 2021 / Published online: 19 October 2021

(C) The Author(s) 2021

\begin{abstract}
Endemic Burkitt lymphoma (eBL) is an aggressive B cell cancer characterized by an IgH/c-myc translocation and the harboring of Epstein-Barr virus (EBV). Evidence accumulates that CD4 + T cells might contribute to eBL pathogenesis. Here, we investigate the presence of CD4 + T cells in primary eBL tissue and their potential dichotomous impact on an EBV-infected pre-eBL cell model using ex vivo material and in vitro co-cultures. In addition, we establish a novel method to study the effect of $I g H / c-m y c$ translocation in primary B cells by employing a CRISPR/Cas9 knock-in approach to introduce and tag de novo translocation. We unprecedently document that CD4+ T cells are present in primary eBL tumor tissue. Furthermore, we demonstrate that CD4 + T cells on the one hand suppress eBL development by killing pre-eBL cells lacking $I g H / c-m y c$ translocation in vitro and on the other hand indirectly promote eBL development by inducing crucial EBV Latency III to Latency I switching in pre-eBL cells. Finally, we show that while the mere presence of an $I g H / c$ - $m y c$ translocation does not suffice to escape CD4 + T-cell-mediated killing in vitro, the CD4 + T-cell-mediated suppression of EBV's Latency III program in vivo may allow cells harboring an $\mathrm{IgH} / \mathrm{c}-\mathrm{myc}$ translocation and additional mutations to evade immune control and proliferate by means of deregulated $c-m y c$ activity, resulting in neoplasia. Thus, our study highlights the dichotomous effects of CD4+ T cells and the mechanisms involved in eBL pathogenesis, suggests mechanisms of their impact on eBL progression, and provides a novel in vitro model for further investigation of $\mathrm{IgH} / \mathrm{c}$ - $\mathrm{myc}$ translocation.
\end{abstract}

Keywords Epstein-Barr virus · T helper cells · Endemic Burkitt lymphoma • CRISPR/CAS9 · Latency III to Latency I switch $\cdot I g H / c-m y c$ translocation

$\begin{array}{llll}\text { Abbreviations } & \text { CRISPR } & \text { Clustered regularly interspaced short palin- } \\ \text { AID } & \text { Activation-induced cytidine deaminase } & & \text { dromic repeats } \\ \text { cRPM } & \text { RPMI medium } & \text { E/T ratio } & \text { Effector/target ratio } \\ \text { CAS9 } & \text { CRISPR-associated protein } 9 & \text { eBL } & \text { Endemic Burkitt lymphoma } \\ \text { CMV } & \text { Cytomegalovirus } & \text { EBNA } & \text { Epstein-Barr nuclear antigen }\end{array}$

Semjon Sidorov

semjon.sidorov@uzh.ch

$\triangle$ Simone Bürgler

simone.buergler@uzh.ch

1 Experimental Infectious Diseases and Cancer Research, Children's Research Center, University Children's Hospital of Zurich, University of Zurich, Zurich, Switzerland

2 Division of Anatomical Pathology, National Health Laboratory Service, Chris Hani Baragwanath Academic Hospital, School of Pathology, University of the Witwatersrand, Johannesburg, South Africa
3 Kempf Und Pfaltz, Histological Diagnostics, Zürich, Switzerland

4 Department of Dermatology, University Hospital Zurich, Zurich, Switzerland

5 Department of Pediatric Hematology and Oncology, Inselspital, Bern University Hospital, University of Bern, Bern, Switzerland

6 Department of Biomedical Research, University of Bern, Bern, Switzerland 


$\begin{array}{ll}\text { EBV } & \text { Epstein-Barr virus } \\ \text { EdU } & \text { 5-Ethynyl-2'-deoxyuridine } \\ \text { FISH } & \text { Fluorescence in situ hybridization } \\ \text { gDNA } & \text { Genomic DNA } \\ \text { GFP } & \text { Green fluorescent protein } \\ \text { IHC } & \text { Immunohistochemistry } \\ \text { LCL } & \text { Lymphoblastoid cell line } \\ \text { LMP } & \text { Latent membrane protein } \\ \text { LN } & \text { Lymph node } \\ \text { qRT-PCR } & \text { Quantitative real-time polymerase chain } \\ & \text { reaction } \\ \text { Tfh } & \text { Follicular T helper } \\ \text { TMC } & \text { Tonsillar mononuclear cell }\end{array}$

\section{Introduction}

Endemic Burkitt lymphoma (eBL), the most frequent type of Burkitt lymphoma, is widespread in sub-Saharan Africa and affects mainly immunocompetent hosts [1]. eBL is thought to originate from germinal center (GC) B cells [2] and is characterized by the presence of an $\mathrm{IgH} / \mathrm{c}-\mathrm{myc}$ translocation, which leads to deregulated expression of the proto-oncogene $c$-myc [3]. The $I g H / c-m y c$ translocation is not sufficient for eBL development, suggesting a multi-step pathogenesis [4]. Additional factors, including mutations [5] and chronic immune-stimulating co-infections such as malaria [6], are required. Importantly, $98 \%$ of eBL tumors harbor Epstein-Barr virus (EBV) [6], though its pathogenic role is incompletely elucidated.

EBV is a B-lymphotropic virus which infects more than $90 \%$ of the world's population, usually with no ill effects [7]. Key for EBV persistence is its ability to evade the host's immune response by entering latency in B cells. During early B cell infection, EBV is found in Latency III program. It transforms B cells into proliferating blasts and is dependent on EBV nuclear antigen 2 (EBNA2) and latent membrane protein 1 (LMP1) expression, as well as Cp promoter $[8,9]$. In vitro, EBV-infected B cells remain in Latency III and proliferate almost indefinitely as lymphoblastoid cell lines (LCLs). In immunocompetent hosts, however, the immune response drives transition from Latency III to the more restricted latency programs II, I, or 0 [10], since the Latency III program is highly immunogenic $[11,12]$. Thus, the vast majority of EBV-infected B cells in vivo are found in Latency I/0, during which only EBNA1, regulated by Qp promoter, is expressed [13]. EBV-infected B cells in Latency I lose proliferative capacity, but become almost undetectable by the immune system [14].

Early eBL cells are thought to derive from EBV-infected B cells that acquire $I g H / c-m y c$ translocation [3], probably through aberrant action of activation-induced cytidine deaminase (AID) [15], upregulated by EBV in Latency III [16].
EBV-infected eBL cells, however, harbor EBV in Latency I, with cell proliferation driven by deregulated c-myc expression due to $\mathrm{IgH} / \mathrm{c}-\mathrm{myc}$ translocation [3]. Therefore, Latency III to Latency I switch seems one of the key steps in eBL development, as it allows EBV-infected pre-eBL cells with an $I g H / c-m y c$ translocation to escape antiviral immunity. How and when this switch happens remains unclear.

The literature suggests that simultaneous expression of $\mathrm{EBV}$ and $\mathrm{eBL}$ growth programs is incompatible within the same cell [17-21]. Latency III depends on high NF- $\mathrm{kB}$ activity, while eBL cells usually show high c-myc activity and lack NF- $\mathrm{KB}$ signaling [17-21]. Furthermore, the EBV Latency III program is dominant over the $c-m y c$ growth program [22-25], as the presence of $I g H / c-m y c$ translocation alone is not enough to turn an EBV-infected B cell into an eBL cell [22, 23], and overexpression of c-myc in Latency III B cells does not induce a switch to Latency I [24, 25]. Therefore, external factors are thought to induce the Latency III-to-Latency I switch in pre-eBL cells, but their specific nature remains unknown.

There is accumulating evidence that CD4 + T cells impact on eBL pathogenesis. Several studies have suggested that $\mathrm{CD} 4+\mathrm{T}$ cells act as cytotoxic killer cells against EBVinfected cells [26-29]. Other studies suggest that CD4+ T cells might support pre-eBL cells, like $\mathrm{T}$ follicular helper (Tfh) cell support healthy B cells, and, therefore, may inadvertently promote eBL development [30-33]. Particularly, in vitro co-culture studies have shown that at lower effector/target $(\mathrm{E} / \mathrm{T})$ ratios $\mathrm{CD} 4+\mathrm{T}$ cells suppress $\mathrm{B}$ cell proliferation [32] by inducing Latency III to Latency I switch, characterized by loss of EBNA2 [32, 33] and LMP1 [33] expression. Lack of suitable in vitro and in vivo models, however, considerably obstacle mechanistic studies of early eBL pathogenesis and immune system contribution to eBL development.

Here, we investigated the potential pathogenic role of $\mathrm{CD} 4+\mathrm{T}$ cells in eBL based on the hypothesis of a dichotomous impact of CD4 $+\mathrm{T}$ cells on eBL development. We hypothesize that $\mathrm{CD} 4+\mathrm{T}$ cells interact with $\mathrm{EBV}$-infected pre-eBL cells, similarly to Tfh cell interaction with a healthy B cell, leading to the suppression of the EBV Latency III program and reduction in EBV-infected cell outgrowth. While the switching to the BL Latency I suppresses the growth of EBV-infected B cells, it protects them from immune recognition. Moreover, we suggest that the Latency switch allows the rare $\mathrm{IgH} / \mathrm{c}$-myc-translocated cells to proliferate by means of deregulated $c-m y c$ activity, resulting in subsequent neoplasia. Thus, we aimed at engineering a novel model of pre-eBL cells harboring an $\mathrm{IgH} / \mathrm{c}-\mathrm{myc}$ translocation to be used in co-cultures with CD4 + T cells in vitro. Using this model, we gathered important insights into $\mathrm{CD} 4+\mathrm{T}$ cells interaction with pre-eBL cells and into their potential role in early events of eBL development. 


\section{Material and methods}

All kits/reagents were used according to manufacturer's instructions unless otherwise stated. Details on antibodies and oligos are given in Tables 1,2 and 3.

\section{Patient material}

The study was conducted according to the Helsinki Declaration 1964 and approved by the regional ethics committees (Kantonale Ethikkommission Zürich, KEK-ZH Nr. $\mathrm{StV} 40 / 05$, and University of the Witwatersrand, Johannesburg, South Africa, Nr. M180294). Human palatine tonsils were obtained from children undergoing routine tonsillectomy at the University Children's Hospital Zurich after informed parental consent. Thirteen archived cases of BL were retrieved from the Division of Anatomical Pathology, National Health Laboratory Service, Chris Hani Baragwanath Academic Hospital, School of Pathology, University of the Witwatersrand, Johannesburg, South Africa. Tissue samples were fixed in $10 \%$ neutral buffered formalin. Ten recuts per patient were performed from paraffin tissue blocks and shipped to Zurich for immunohistochemistry (IHC). For additional patient information, see Supplementary Table 1.

\section{Cell culture}

Cells were cultured in cRPMI medium, prepared as described in [40]. For co-culture experiments, cRPMI media was supplemented with $20 \mathrm{U} / \mathrm{ml}$ of human recombinant IL-2 (Roche), referred as co-culture media.

\section{Isolation of tonsillar mononuclear cells from tonsils}

Tonsillar mononuclear cells (TMCs) were isolated from fresh tonsils as described [34].

\section{Preparation of EBV virus stock and generation of lymphoblastoid cell lines}

Concentrated EBV virus stock was prepared using B95-8/ ZHT cell line (kind gift from Micah Luftig) as described [35] and used for generation of lymphoblastoid cell lines (LCLs) from TMCs [34].

\section{Isolation and expansion of CD4 + T cells}

CD4 + T cells were isolated from TMCs using the CD4 MicroBeads and the autoMACS Pro Separator (Miltenyi Biotec). CD4 + T cells were polyclonally expanded for 7-10d using CD3/CD28 beads (Dynabeads ${ }^{\circledR}$ Human
T-Activator CD3/CD28, Gibco by Thermo Fisher Scientific). Prior to co-culture, $\mathrm{CD} 4+\mathrm{T}$ cells were rested by withdrawal of IL-2 and CD3/CD28 beads for 24-48 h.

\section{Co-culture setup}

Co-cultures between autologous LCLs and CD4 + T cells were set up in 6-well flat-bottom plates (Sarstedt) in $3 \mathrm{ml}$ of co-culture media/well at $1.5 \mathrm{mio} /$ well total cell density. Anti-CD3/CD28 beads were used to stimulate T cells in coculture, unless stated "rested." For 4:1 T cell/LCL cell ratio, $1.2 \mathrm{mio} /$ well CD4 $+\mathrm{T}$ cells and $0.3 \mathrm{mio} /$ well $\mathrm{LCL}$ were initially plated. For $1: 1 \mathrm{~T}$ cell/LCL ratio, $0.75 \mathrm{mio} /$ well of both $\mathrm{CD} 4+\mathrm{T}$ cells and LCL were plated. For control conditions, $\mathrm{CD} 4+\mathrm{T}$ cells and LCL were cultured alone at corresponding cell densities. Cells were co-cultured for up to $9 \mathrm{~d}$, split every second day.

\section{Post-co-culture separation of LCLs and CD4 + T cells}

LCLs and CD4 + T cells from co-culture were separated using CD19 MicroBeads and autoMACS Pro Separator (both Miltenyi Biotec). Purity post-separation was determined using flow cytometry. Cells were then lysed for protein and RNA isolation.

\section{Flow cytometry}

For all stainings, cells were treated with Zombie viability dye and $\mathrm{Fc}$ receptor blocker and stained with anti-CD19 and anti-CD4 gating antibodies (Table 1). For surface marker stainings, cells were then stained with a corresponding panel of target-specific or isotype antibodies, washed and immediately acquired by flow cytometer. For apoptosis assay, after the surface staining cells were washed twice in Annexin $\mathrm{V}$ binding buffer (10 mM HEPES, $140 \mathrm{mM} \mathrm{NaCl}$, $5 \mathrm{nM} \mathrm{CaCl}_{2}$ ), they were stained with anti-human Annexin $\mathrm{V}$ antibody for $15 \mathrm{~min}$ on ice and then immediately acquired by flow cytometer. EdU incorporation assay was performed using Click-iT ${ }^{\mathrm{TM}}$ Plus EdU Alexa Fluor 647 Flow Cytometry Assay Kit (Invitrogen). For cell cycle analysis, FxCycle ${ }^{\mathrm{TM}}$ dye (Thermo Scientific) was added $30 \mathrm{~min}$ prior to acquisition by flow cytometer. Cytokine/transcription factor staining was performed using Foxp3/Transcription Factor Staining Buffer Kit (eBioscience by Thermo Scientific). Briefly, cytokine production in co-culture was induced by adding $1 \mu \mathrm{g} / \mathrm{ml}$ PMA (Abcam) and $1 \mu \mathrm{g} / \mathrm{ml}$ Ionomycin (Abcam) for $4 \mathrm{~h}$ before harvesting. Brefeldin A at $5 \mu \mathrm{g} / \mathrm{ml}$ (Abcam) was added for $3 \mathrm{~h}$ prior to harvesting to induce cytokine accumulation in the cell. After the surface and viability stainings, cells were fixed, permeabilized and then stained with a corresponding panel of target-specific or isotype intracellular antibodies (see Table 1). BD LSRFortessa ${ }^{\mathrm{TM}}$ 
Table 1 Antibody details

\begin{tabular}{|c|c|c|c|c|c|c|c|}
\hline & $\begin{array}{l}\text { Staining antibody/ } \\
\text { reagent }\end{array}$ & Supplier & $\begin{array}{l}\text { Concentration } \\
\text { (ul/100ul staining } \\
\text { buffer) }\end{array}$ & Clone & Cat Number & Dilution & Diluted in \\
\hline \multirow[t]{33}{*}{ Flow cytometry (FC) } & $\begin{array}{l}\text { Human TruStain } \\
\text { FcX }\end{array}$ & BioLegend & 1.25 & N/A & 422,302 & & \\
\hline & $\begin{array}{l}\text { Zombie Red Viabil- } \\
\text { ity dye }\end{array}$ & BioLegend & 0.1 & N/A & 423,109 & & \\
\hline & $\begin{array}{l}\text { Zombie NIR } \\
\text { Viability dye }\end{array}$ & BioLegend & 0.1 & N/A & 423,105 & & \\
\hline & Annexin V-APC & BioLegend & 1.25 & N/A & 640,919 & & \\
\hline & FxCycle Violet & Thermo Scientific & 1 & N/A & R37166 & & \\
\hline & CD19-APC/Cy7 & BioLegend & 2.5 & HIB19 & 302,218 & & \\
\hline & $\begin{array}{l}\text { CD19-AlexaFluor } \\
700\end{array}$ & BioLegend & 1.25 & HIB19 & 302,226 & & \\
\hline & CD19-APC/Cy7 & BioLegend & 5 & HIB19 & 302,218 & & \\
\hline & CD4-BV711 & Thermo Scientific & 2.5 & OKT4 & 67-0049-42 & & \\
\hline & CD4—PerCp/Cy5.5 & BioLegend & 1.25 & RPA-T4 & 300,529 & & \\
\hline & CD40—PE/Cy7 & BioLegend & 2.5 & $5 \mathrm{C} 3$ & 334,321 & & \\
\hline & CD40L-BV421 & BioLegend & 5 & $24-31$ & 310,823 & & \\
\hline & CD28-BV711 & BioLegend & 5 & CD28.2 & 302,947 & & \\
\hline & CD80-BV421 & BioLegend & 2.5 & 2D10 & 305,221 & & \\
\hline & CD86-BV711 & BioLegend & 1.25 & IT2.2 & 305,439 & & \\
\hline & $\mathrm{OX} 40-\mathrm{APC}$ & BioLegend & 5 & $11 \mathrm{C} 3.1$ & 326,307 & & \\
\hline & $\mathrm{OX} 40 \mathrm{~L}-\mathrm{PE}$ & BioLegend & 2.5 & ACT35 & 350,007 & & \\
\hline & ICOS-L-APC & BioLegend & 5 & $11 \mathrm{C} 3.1$ & 326,307 & & \\
\hline & ICOS-PE/Cy7 & BioLegend & 5 & $2 \mathrm{D} 3$ & 309,407 & & \\
\hline & FASL-PE & BioLegend & 2.5 & C398.4A & 313,519 & & \\
\hline & $\begin{array}{l}\text { FAS_PE/Dazzle } \\
594\end{array}$ & BioLegend & 5 & NOK-1 & 306,406 & & \\
\hline & $\begin{array}{l}\text { HLADR-PerCp/ } \\
\text { Cy5.5 }\end{array}$ & BioLegend & 1.25 & DX2 & 305,633 & & \\
\hline & $\begin{array}{l}\text { HLA A,B,C- } \\
\text { BV510 }\end{array}$ & BioLegend & 5 & L243 & 307,629 & & \\
\hline & IFNg-APC/Cy7 & BioLegend & 5 & $\mathrm{~W} 6 / 32$ & 311,435 & & \\
\hline & T-bet-BV711 & BioLegend & 2.5 & B27 & 506,523 & & \\
\hline & IL13-BV421 & BioLegend & 2.5 & $4 \mathrm{~B} 10$ & 644,819 & & \\
\hline & GATA3-Alexa 488 & BioLegend & 2.5 & JES10-5A2 & 501,915 & & \\
\hline & IL21—Alexa 647 & BioLegend & 2.5 & 16E10A23 & 653,807 & & \\
\hline & bcl6-PE & BioLegend & 2.5 & $3 \mathrm{~A} 3-\mathrm{N} 2$ & 513,005 & & \\
\hline & $\begin{array}{l}\text { CD54-PerCp/ } \\
\text { eFluor } 710\end{array}$ & Thermo Scientific & 5 & HA58 & $46-0549-41$ & & \\
\hline & CD10—PE/Сy5 & BioLegend & 20 & HI10a & 555,376 & & \\
\hline & $\mathrm{CD} 23-\mathrm{BV} 421$ & BioLegend & 5 & EBVCS-5 & 338,521 & & \\
\hline & CD39-BV510 & BioLegend & 5 & $\mathrm{~A} 1$ & 328,219 & & \\
\hline \multirow[t]{2}{*}{$\mathrm{FC}$} & CD38-APC & Thermo Scientific & 5 & HIT2 & $17-0389-41$ & & \\
\hline & CD58-PE/Cy7 & BioLegend & 5 & $\mathrm{TS} 2 / 9$ & 330,915 & & \\
\hline
\end{tabular}


Table 1 (continued)

\begin{tabular}{|c|c|c|c|c|c|c|c|}
\hline & $\begin{array}{l}\text { Staining antibody/ } \\
\text { reagent }\end{array}$ & Supplier & $\begin{array}{l}\text { Concentration } \\
\text { (ul/100ul staining } \\
\text { buffer) }\end{array}$ & Clone & Cat Number & Dilution & Diluted in \\
\hline \multirow[t]{8}{*}{ Western Blot } & $\begin{array}{l}\text { Mouse anti-human } \\
\text { EBNA2 }\end{array}$ & Abcam & & PE2 & ab90543 & $1: 1000$ & $5 \%$ Milk/TBS-T \\
\hline & $\begin{array}{l}\text { Mouse anti-human } \\
\text { LMP1 }\end{array}$ & Abcam & & CS $1-4$ & ab78113 & $1: 1000$ & $5 \%$ Milk/TBS-T \\
\hline & $\begin{array}{l}\text { Rabbit anti-human } \\
\text { c-myc }\end{array}$ & Abcam & & Y69 & ab32072 & $1: 2500$ & $5 \%$ Milk/TBS-T \\
\hline & $\begin{array}{l}\text { Rabbit anti-human } \\
\beta \text {-actin }\end{array}$ & Abcam & & polyclonal & $4967 \mathrm{~S}$ & $1: 1000$ & $5 \%$ Milk/TBS-T \\
\hline & $\begin{array}{l}\text { Rabbit anti-human } \\
\beta \text {-actin }\end{array}$ & Abcam & & polyclonal & $4967 \mathrm{~S}$ & $1: 1000$ & $\begin{array}{l}\text { 1X Blocker TM } \\
\text { FL Fluores- } \\
\text { cent Blocking } \\
\text { Buffer }\end{array}$ \\
\hline & $\begin{array}{l}\text { Horse anti-mouse } \\
\text { HRP (secondary) }\end{array}$ & Cell Signaling & & polyclonal & $7076 \mathrm{~S}$ & $1: 1000$ & $5 \%$ Milk/TBS-T \\
\hline & $\begin{array}{l}\text { Goat anti-rabbit HRP } \\
\text { (secondary) }\end{array}$ & Cell Signaling & & polyclonal & $7074 S$ & $1: 2500$ & 5\% Milk/TBS-T \\
\hline & $\begin{array}{l}\text { Anti-rabbit Alexa } \\
\text { Fluor } 488 \text { (second- } \\
\text { ary) }\end{array}$ & Thermo Scientific & & polyclonal & A32731 & $\begin{array}{l}\text { 1:10,000 } \\
\quad \text { (Fluores- } \\
\text { cent) }\end{array}$ & $\begin{array}{l}\text { 1X Blocker TM } \\
\text { FL Fluores- } \\
\text { cent Blocking } \\
\text { Buffer }\end{array}$ \\
\hline \multirow[t]{3}{*}{$\mathrm{IHC}$} & $\begin{array}{l}\text { Mouse anti-human } \\
\text { CD3 }\end{array}$ & Dako & & F7.2.38 & & $1: 100$ & \\
\hline & $\begin{array}{l}\text { mouse anti-human } \\
\text { CD8 }\end{array}$ & Cell Marque & & C8/144B & & $1: 90$ & \\
\hline & $\begin{array}{l}\text { mouse anti-human } \\
\text { CD4 }\end{array}$ & Novocastra & & 4B12 & & $1: 80$ & \\
\hline
\end{tabular}

(BD Biosciences) with FACSDiva ${ }^{\mathrm{TM}}$ software was used for data acquisition; FlowJo 10.6 software was used for postacquisition analysis.

\section{Western blotting}

For total protein extraction, cells were lysed in RIPA buffer (Sigma-Aldrich) with protease inhibitor cocktail (cOmplete Tablet mini, Roche Diagnostics) and sonicated using an EpiShear ${ }^{\mathrm{TM}}$ Probe Sonicator (Active Motif) at $40 \%$ amplitude for $2 \mathrm{~s}$. Protein concentration was measured using Pierce $^{\mathrm{TM}} 660 \mathrm{~nm}$ Protein Assay Kit (Pierce by Thermo Scientific). Proteins were separated on 4-12\% NuPage Gels (Invitrogen by Thermo Scientific) and transferred to either nitrocellulose membranes (GE Healthcare Life Science) or PVDF membranes (Thermo Scientific). Nitrocellulose membranes were blocked with $5 \%$ nonfat dry milk and used for detection with HRP secondary antibodies. PVDF membranes, blocked with $1 \mathrm{X}$ Blocker TM FL Fluorescent Blocking Buffer (Thermo Scientific) and fluorescent secondary antibodies for $\beta$-actin were used. HRP signal was detected using Amersham ECL ${ }^{\text {TM }}$ Western Blotting Reagent
(GE Healthcare Life Science). ChemiDoc Imaging System (Bio-Rad Laboratories) was used to acquire both HRP and fluorescent signal. Band intensity (volume) for proteins of interest was quantified using ImageLab 6 (Bio-Rad Laboratories) software and normalized to loading control ( $\beta$-actin).

\section{qRT-PCR}

RNA was isolated using either Quick-RNA MiniPrep Kit (Zymo Research) with additional DNase treatment (ezDNase $^{\mathrm{TM}}$, Thermo Scientific). RNA concentration was measured using NanoDrop (Thermo Scientific). cDNA was generated using High-Capacity cDNA Reverse Transcription Kit (Thermo Scientific). Gene expression was measured using either pre-designed TaqMan assays (IDT) or in-house designed primer-probe mixes (synthesized by Microsynth). Primer/probe sequences for Cp and Qp promoter usage assay were obtained from [36]. qRT-PCR was performed on a CFX384 Touch Real-Time PCR Detection System (Bio-Rad Laboratories AG) or 7900HT Fast Real-Time PCR System (Thermo Fisher Scientific). LCL gene expression was normalized to the geometric mean of 2 endogenous controls 
Table 2 List of PCR, gDNA PCR and qRT-PCR primer/probes

\begin{tabular}{|c|c|c|c|c|}
\hline & Gene/Sequence name & Direction & Sequence or assay ID & Supplier \\
\hline \multirow[t]{6}{*}{ Cloning (PCR) } & c-myc PCR-1F & Forward & 5'-CCGCCATCTTTAGCAACTTTC-3' & Microsynth (custom) \\
\hline & c-myc PCR-1R & Reverse & 5'-CACAGCAGAAGGTGATGGGTA-3' & \\
\hline & IgH PCR-1F & Forward & 5'-CGAGATGCCTGAACAAACCA-3' & \\
\hline & IgH PCR-1R & Reverse & 5'-CTTGCTTTGGCCTCAATTCC-3' & \\
\hline & GFP PCR-1F & Forward & 5'-CCG CGT TAC ATA ACT TAC GG-3' & \\
\hline & GFP PCR-1R & Reverse & 5'-AAC TTG TTT ATT GCA GCT TAT AAT GGT-3' & \\
\hline \multirow[t]{6}{*}{ gDNA PCR } & gDNA nPCR-1F & Forward & 5'-ATC CGC CAT CTT TAG CAA CTT T-3' & \\
\hline & gDNA nPCR-1R & Reverse & 5'-CTG AGC ATT GCA GGT TGG TC-3' & \\
\hline & gDNA nPCR-2F & Forward & 5'-AAT TCA TCT GCT TCC AGC TT-3' & \\
\hline & gDNA nPCR-2R & Reverse & 5'-TAT GGA GAA CCG GTA ATG GCA-3' & \\
\hline & gDNA nPCR-3F & Forward & 5'-TAC CCT ATG AGG TCA AGC TG-3' & \\
\hline & gDNA nPCR-3R & Reverse & 5'-ACA AAC CAG GGG TCT TAG TG-3' & \\
\hline \multirow[t]{26}{*}{ qRT-PCR } & gDNA nPCR-4F & Forward & 5'-TAT GAT GGT CAA AAC GCA GTC-3' & \\
\hline & gDNA nPCR-4R & Reverse & 5'-CCC CCA CGT CTT AGA AAC TC-3' & \\
\hline & EBNA2 & Forward & 5'-GGG ATG CCT GGA CAC AAG AG-3' & \\
\hline & & Reverse & 5'-CAT GCC CGA CGT CAT ATC CT-3' & \\
\hline & & Probe & FAM-5'-CATCACCTCTTGATAGGGATCCGC-3'-BHQ1 & \\
\hline & LMP1 & Forward & 5'-TGG AGC CCT TTG TAT ACT CCT-3' & \\
\hline & & Reverse & 5'TGC CTG TCC GTG CAA ATT C-3' & \\
\hline & & Probe & FAM-5'-TGATCACCCTCCTGCTCATCGCTCT-3'-BHQ1 & \\
\hline & EBNA1 Cp & Forward & 5'-TGC CTG AAC CTG TGG TTG G-3' & \\
\hline & & Reverse & 5'-CAT GAT TCA CAC TTA AAG GAG ACG G-3' & \\
\hline & & Probe & FAM-5'-TCCTCTGGAGCCTGACCTGTG ATC G-3'-BHQ1 & \\
\hline & EBNA1 Qp & Forward & 5'-GTG CGC TAC CGG ATG GC-3' & \\
\hline & & Reverse & 5'-CAT GAT TCA CAC TTA AAG GAG ACG G-3' & \\
\hline & & Probe & FAM-5'-TCCTCTGGAGCCTGACCTGTGATCG-3'-BHQ1 & \\
\hline & bc16 & & Hs.PT.56a.19673829.g (Dye: FAM) & IDT® \\
\hline & c-myc & & Hs.PT.58.26770695 (Dye: FAM) & IDT $®$ \\
\hline & $\mathrm{IFN} \gamma$ & & Hs.PT.58.3781960 (Dye: FAM) & IDT® \\
\hline & IL-13 & & Hs00174379_m1 (Dye: FAM) & Thermo Fisher \\
\hline & IL-21 & & Hs.PT.58.22750196 (Dye: FAM) & IDT® \\
\hline & TBX21 & & Hs.PT.58.3936407 (Dye: FAM) & IDT® \\
\hline & GATA3 & & Hs.PT.58.4308511 (Dye: FAM) & IDT® \\
\hline & bcl6 & & Hs.PT.56a.19673829.g (Dye: FAM) & IDT® \\
\hline & POLR2A & & Hs.PT.39a.19639531 (Dye: FAM) & IDT® \\
\hline & UBC & & Hs.PT.39a.22214853 (Dye: Cy5) & IDT® \\
\hline & TBP & & Hs.PT.39a.22214825 (Dye: FAM) & IDT® \\
\hline & YWHAZ & & Hs.PT.39a.22214858 (Dye: FAM) & IDT® \\
\hline
\end{tabular}

(TBP and YWHAZ) using dCt method. Endogenous controls were selected based on stability pre-validation using qbase 3.2 software.

\section{Fluorescent in situ hybridization (FISH)}

In total, 100000 LCLs were attached to microscopy slides using Cytospin funnels (500 rpm for $5 \mathrm{~min}$ at RT), fixed with $70 \%$ ethanol ( $15 \mathrm{~min}$ at $4 \mathrm{C}$ ) and stored at $-20 \mathrm{C}$ until the day of the analysis.
$2.5 \mu \mathrm{l}$ of $\mathrm{IgH} / \mathrm{c}-\mathrm{myc}$ translocation dual fusion probe (LPH-041, Cytocell) was added per slide, and slides were incubated in thermal cycler $(2 \mathrm{~min}$ at $75 \mathrm{C}$ then at $37 \mathrm{C}$ overnight). Next day, slides were washed with $0.4 \mathrm{xSSC}$ $(2 \mathrm{~min}$ at $72 \mathrm{C})$ and $2 \mathrm{xSSC}+0.05 \%$ Tween $-20(1 \mathrm{~min}$ at RT). Samples were then counterstained with DAPI, and images were acquired using Metafer Slide Scanning Platform (MetaSystems). 
Table 3 crRNA, ssDNA, PCR primer sequences

\begin{tabular}{|c|c|}
\hline Sequence name & Sequence $\left(5^{\prime}-3^{\prime}\right)$ \\
\hline crRNA IgH1 & 5' AltR1-CCGUAAAAACCUACUUGACCGUUUUAGAGCUAUGCU-AltR2-3' \\
\hline crRNA IgH7 & 5' AltR1-CCGAAGGAUCGCUUUAACCGGUUUUAGAGCUAUGCU-AltR2-3' \\
\hline crRNA IgH10 & 5' AltR1-CCUCGGUUAAAGCGAUCCUUGUUUUAGAGCUAUGC-AltR2-3' \\
\hline crRNA c-myc4 & 5' AltR1-GGACGGCAGCCACCGUUUCUGUUUUAGAGCUAUGCU-AltR2-3' \\
\hline crRNA c-myc5 & 5' AltR1-GCCGUCCUGACAGGGGCUUAGUUUUAGAGCUAUGCU-AltR2-3' \\
\hline crRNA c-myc6 & 5' AltR1-GCCCCGGUCUUGAUGAGAGCGUUUUAGAGCUAUGCU-AltR2-3' \\
\hline GFP PCR-1F & 5'-CCG CGT TAC ATA ACT TAC GG-3' \\
\hline GFP PCR-1R & 5'-AAC TTG TTT ATT GCA GCT TAT AAT GGT-3' \\
\hline STR1-F & 5' GGC TTC TGA GGC GGA AAG' \\
\hline STR1-R & 5' CTT TTT ACG GTT CCT GGC CTT' \\
\hline IgH gene block & $\begin{array}{l}\text { 5'cggaaagaaccagcGGCGCGAGTGCCAGATTCCTGGGAAATCAGCCTACAAGGCTCCTGCGGGAAGGAACCTCC } \\
\text { ACTGCCAGAAGTCCTTAGGGCATCTAAGTGATCAGACACCGTCAGGGATTCTTTGCCCCGTAAAAACCT } \\
\text { ACTTGACCAGGGACACGTGCCAGGTAAATTTCCTTCACATTTACTTCAACCTTATTGCATACTCATTTTAGT } \\
\text { ATTAAAACCTTTAATAAAATGCTCCTATTCCTTCACACTTTTTTTCTATGAGATCTCAAATACCCCTTCTTG } \\
\text { CTATTAAAAAAAATCACTTATTATTCACCAGCCCAATATTTTAAAAGTAAAAATAATAAGCCAAGGCCA } \\
\text { GGAGCGATGACTCGCACTTGTATTCCCAGCAGTTTCAGAGGCAAAGGCCGAAGGATCGCTTTAACCGCG } \\
\text { TTACATAACTTACGG-3' }\end{array}$ \\
\hline c-myc gene block & $\begin{array}{l}\text { 5'TAAGCTGCAATAAACAAGTTCTCATCAAGACCGGGGCTACGCGTCCCTCCTGGCTGGATTCACCCACTC } \\
\text { CGACAGTTCTCTTTCCAGCCAATAAAGAATTTAAGATGCAGGTTGACACACAGCGCACCTCATAATTCT } \\
\text { AAAGAAAATATTTCACGATTCGCTGCTGTGCAGCGATCTTGCAGTCCTACAGACACCGCTCCTGAGACA } \\
\text { CATTCCTCAGCCATCACTAAGACCCCTGGTTTGTTCAGGCATCTCGTCCAAATGTGGCTCCCCAAGCCC } \\
\text { CCAGGCTCAGTTACTCCATCAGACGCACCCAACCTGAGTCCCATTTTCCAAAGGCATCGGAAAATCCAC } \\
\text { AGAGGCTCCCAGATCCTCAAGGCACCCCAGTGCCCATCCCCTCCTGGCCAGTCCGCCCAGGTCCCCTCG } \\
\text { GAACATCTAGCcaaaaggccaggaac-3' }\end{array}$ \\
\hline GFP + CMV ssDNA & 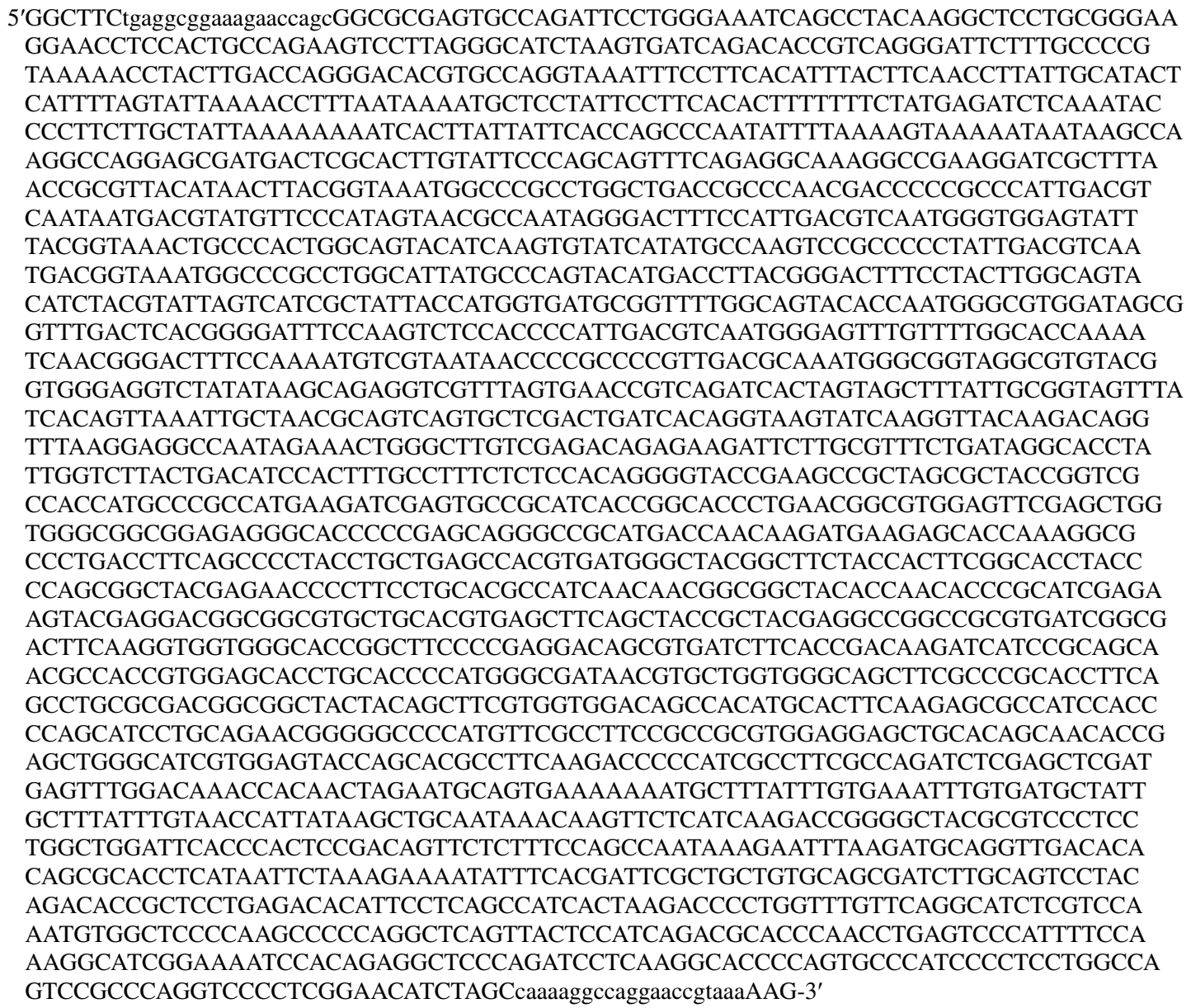 \\
\hline
\end{tabular}


Table 3 (continued)

\begin{tabular}{ll}
\hline Sequence name & Sequence $\left(5^{\prime}-3^{\prime}\right)$ \\
\hline pmax-GFP plasmid & http://www.addgene.org/vector-database/3525/ \\
pcDNA3.1 & https://www.addgene.org/vector-database/2093/ \\
\hline
\end{tabular}

\section{Immunohistochemistry (IHC)}

Biopsy specimens were fixed in $10 \%$ buffered formalin, embedded in paraffin and stained with hematoxylin and eosin (H\&E). The immunohistochemical stains were conducted using a Leica BOND-MAX stainer (Leica Microsystems). Antigen retrieval included the application of ER2 solution (Leica Microsystems). Sections of human tonsils were used as positive controls.

\section{Evaluation of the IHC slides and data analysis}

All slides were evaluated by one of the coauthors (W.K.) blinded to clinical data. Total cell number of the biopsy was estimated by counting cells based on hematoxylin and eosin staining, and the number of marker-positive cells was estimated by counting marker-positive cells. The results were given in percentage of the whole number of cells compared to the entire infiltrate and scored as (0) negative, (1) $<1 \%$, (2) $1-5 \%$, (3) $6-10 \%$, (4) $11-20 \%$, (5) $21-30 \%$. Individual scores can be found in Supplementary Fig. 2. Representative images were taken with Axio Observer Z1 (Zeiss) and Digital Camera ORCA Flash 4.0 (Hamamatsu) using TL Brightfield channel. Images were not edited except of adjustment of Black/White intensity.

\section{Generation of $I g H / c-m y c+L C L s$ using CRISPR/CAS9 approach}

crRNAs for $I g H$ and $c-m y c$ regions were designed using the online tool (www.crispr.mit.edu). CAS9 ribonuclear protein complexes (RNPs) were formed in vitro from specific crRNAs (synthesized by IDT), standardized tracrRNA (Alt-R CRISPR-CAS9 tracrRNA, IDT) and CAS9 protein (Alt-R S.p. CAS9 Nuclease V2, IDT). Then, 200 000 LCLs were electroporated with CAS9 RNPs $(1.5 \mu \mathrm{M}$ each), ssDNA template $(1 \mu \mathrm{g} /$ transfection $)$ and $1.8 \mu \mathrm{M}$ of transfection enhancer (IDT) in $10 \mu \mathrm{l}$ tips using Neon Transfection System (Thermo Scientific) at $1400 \mathrm{~V}$, $10 \mathrm{~ms}, 3$ pulses. Electroporated cells were outgrown for 2 weeks, and GFP + cells were flow-sorted using FACSAria Fusion cell sorter (BD Biosciences). Cells were grown for 2 additional weeks, and purity was regularly checked by monitoring percentage of GFP + cells by flow cytometer. Additional sorts were performed if percentage of GFP + cells dropped significantly.

\section{Generation of ssDNA for GFP knock-in}

ssDNA insert was designed to consist of GFP driven by CMV promoter, flanked by two 400 bp regions homologous to $I g H$ and $c-m y c$ regions near to breakpoint. $I g H$ and $c$-myc homology regions were added in order to facilitate specific integration of GFP $+\mathrm{CMV}$ insert into reciprocal translocation breakpoint. ssDNA insert was generated using Guide-it Long ssDNA production system (Takara Bio). Briefly, we assembled 400 bp homology regions (ordered as GeneBlocks from IDT), GFP + CMV insert (amplified by PCR from pmax-GFP plasmid (Amaxa, Lonza) using GFP-PCR1 primers) and backbone from pcDNA3.1 plasmid (Invitrogen, Thermo Scientific) using In-Fusion HD Cloning Plus kit (Takara Bio). Then, we generated PCR product using Phusion High-Fidelity DNA polymerase (Thermo Scientific) and STR1 primers and digested sense strand of PCR using Strandase enzyme (from ssDNA production system). ssDNA was then isolated using NucleoSpin Gel and PCR Clean-Up Kit (Takara Bio).

\section{gDNA PCR}

Genomic DNA (gDNA) was isolated using DNAeasy Blood and Tissue Kit (Qiagen). DNA concentration was determined by NanoDrop (Thermo Scientific). PCR was performed using Phusion High-Fidelity DNA polymerase (Thermo Scientific). The second round of nested PCR was performed by diluting product of first-round PCR 1:100 in $\mathrm{ddH}_{2} \mathrm{O}$.

\section{Statistical analysis and graph design}

Statistical analysis was performed using GraphPad Prism 8.4.3 (GraphPad Software). Graphs and drawings were created using GraphPad Prism 8.4.3 (GraphPad Software) and PowerPoint 2019 (Microsoft Corporation).

\section{Results}

\section{CD4 + T cells are present in primary eBL tissue}

Given that the presence of CD4 + T cells in primary eBL tumors has not been reported before, we assessed the 
presence and frequency of $\mathrm{T}$ cells in eBL tissue from 13 patients using IHC. CD3 +, CD $4+$ and $\mathrm{CD} 8+$ cells were present in all eBL samples, mostly at similar frequencies (1-5\% of total cells), independent of tumors' anatomic origin (Fig. 1b). However, CD3 + and CD8 + cells appear to be more numerous as compared to CD4 + cells (Fig. 1a and b).

The above results unprecedentedly show that CD4 + T cells are present in primary eBL tumor tissue and thus likely are present at the site of eBL development, suggesting that they may contribute to eBL pathogenesis.

\section{CD4 + T cells suppress pre-eBL cell outgrowth in vitro by reducing their viability}

Having demonstrated the presence of $\mathrm{CD} 4+\mathrm{T}$ cells in primary eBL tissue, we addressed their possible impact on preeBL cells. To this end, we set up co-cultures of polyclonal aCD3/CD28 beads-activated CD4 + T cells with autologous LCLs and assessed LCL proliferation, viability and cell cycle phases using flow cytometry. We chose LCLs to model pre-eBL EBV-infected B cell for two reasons: First, EBV in LCLs is in Latency III, as it is in pre-eBL cells prior to acquiring the $I g H / c-m y c$ translocation; and second, LCLs derived from tonsils allow setting up co-cultures with autologous $\mathrm{CD} 4+\mathrm{T}$ cells. We used polyclonally activated $\mathrm{CD} 4+\mathrm{T}$ cells rather than $\mathrm{EBV}$-specific CD4 + T cell lines, since this allows working with a heterogeneous pool of CD4 + T cells, as expected to be found in lymph nodes/ tonsils during eBL initiation. Moreover, polyclonal stimulation may mimic chronic stimulation of $\mathrm{CD} 4+\mathrm{T}$ cells as in chronic malaria with which eBL is tightly associated [37].

In contrast to previous reports [32], we could not detect any effect of CD4 $+\mathrm{T}$ cells on LCL proliferation (Fig. 2a, d), nor on the relative percentage of LCLs in different T cell cycle phases (Fig. 2b, e) at any of the time points assessed, strongly suggesting that $\mathrm{CD} 4+\mathrm{T}$ cells have no effect on $\mathrm{LCL}$ proliferation in our co-culture model. However, we observed a markedly reduced viability of LCLs proportionally to the number of $\mathrm{CD} 4+\mathrm{T}$ cells used, while the proportion of apoptotic cells was longitudinally not affected (Fig. 2c, f).

These results suggest that $\mathrm{CD} 4+\mathrm{T}$ cells suppress preeBL cell outgrowth by reducing their viability, rather than by affecting their proliferation.

\section{CD4 + T cells induce switch toward eBL phenotype in pre-eBL cells}

As CD4 $+\mathrm{T}$ cells reduced the viability of pre-eBL cells in our in vitro system, we hypothesized that $\mathrm{CD} 4+\mathrm{T}$ cells may promote eBL development indirectly by suppressing the immunogenic EBV Latency III program, allowing preeBL cells to escape immune control. To test this, we analyzed changes in expression of several crucial EBV and BL markers in LCLs after co-culture with autologous CD4+ T cells. CD4 + T cells suppressed EBNA2 expression on both mRNA (Fig. 3a) and protein (Fig. 3b, Supplementary Fig. 1) levels and reduced Cp promoter usage in LCLs (Fig. 3c). Furthermore, activated CD4 $+\mathrm{T}$ cells induced stronger suppression of EBNA2 protein than non-activated T cells (Fig. 3b). Notably, there was no effect of CD4 $+\mathrm{T}$ cells on LMP1 mRNA (Fig. 3a) or protein (Fig. 3d, Supplementary Fig. 1) levels nor on Qp promoter usage (Fig. 3c). This suggests that while $\mathrm{CD} 4+\mathrm{T}$ cells initiate switch from the dominant Latency III toward Latency I by decreasing EBNA2 expression, the switch is not complete as in eBL, where LMP1 expression is absent. Furthermore, while we did not observe any effect of CD4 $+\mathrm{T}$ cells on $c$-myc expression levels (Supplementary Figs. 1, 10), CD4 + T cells upregulated bcl6 mRNA expression in LCLs (Supplementary Fig. 10). As $b c l 6$ is one of the key markers of eBL, this further supports the notion that $\mathrm{CD} 4+\mathrm{T}$ cells initiate phenotypic changes in LCLs leading to eBL.

Overall, these data suggest that while CD4 + T cells do not directly promote pre-eBL cell outgrowth, by reducing EBNA2 expression they initiate a switch of EBV Latency toward an eBL-like phenotype. This, in turn, may promote the switch of cells with eBL-associated mutations and translocations to the EBV Latency I program through suppression of dominant EBV phenotype Latency III.

\section{CD4 + T cells can interact with pre-BL cells via both contact-dependent and soluble mediators}

Next, we wanted to gain information about the possible mechanisms underlying the changes in viability and gene expression observed in LCLs upon co-incubation with autologous CD4 $+\mathrm{T}$ cells. To this end, we first assessed the expression of several co-stimulatory molecules pairs, known to be involved in antigen-presenting cell (APC)-T cell interaction [38], using flow cytometry. LCLs in co-culture with CD4 + T cells expressed high levels of CD80/86 and CD40 as well as lower but detectable levels of ICOS-L and OX40L (Fig. 4a, 4b, Supplementary Figure S2a), while CD4 + T cells expressed OX40, CD40L and ICOS as well as low levels of CD28 (Fig. 4c, 4d, Supplementary Figure $\mathrm{S} 2 \mathrm{~b})$. Thus, both the CD4 + T cells and the LCLs expressed their part of the co-stimulatory pairs of the four pathways we investigated, supporting the notion that $\mathrm{CD} 4+\mathrm{T}$ cells can affect the phenotype of LCL through conventional T-B cell interaction pathways. Furthermore, we could observe a downregulation of $\mathrm{CD} 40 \mathrm{~L}$ on $\mathrm{CD} 4+\mathrm{T}$ cells upon co-culture with LCLs (Fig. 4g), indicating an active CD40L-CD40 interaction.

Secondly, we assessed the CD4 + T helper subset composition and $\mathrm{CD} 4+\mathrm{T}$ cell-derived cytokines in co-culture using both flow cytometry and qRT-PCR. We observed 
Fig. $1 \mathrm{CD} 4+\mathrm{T}$ cells are present in primary eBL tissue. Recuts from $13 \mathrm{eBL}$ patient biopsy samples were stained for CD3, CD4 and CD8 markers. a Images of CD3, CD4 and CD8 stainings from one representative $\mathrm{BL}$ patient (BL13) at $5 \times$ or $20 \times$ resolution. At $5 \times$ resolution measure bar is $200 \mu \mathrm{m}$, at $20 \times$ resolution measure bar is $50 \mu \mathrm{m}$ for all images. b Mean IHC evaluation score for 13 patients used for the analysis. $p$ values were calculated using paired one-way ANOVA with Sidak's test for multiple comparisons. $p>0.05$ not significant (n.s.), $p<0.1 *$ a

$5 x$
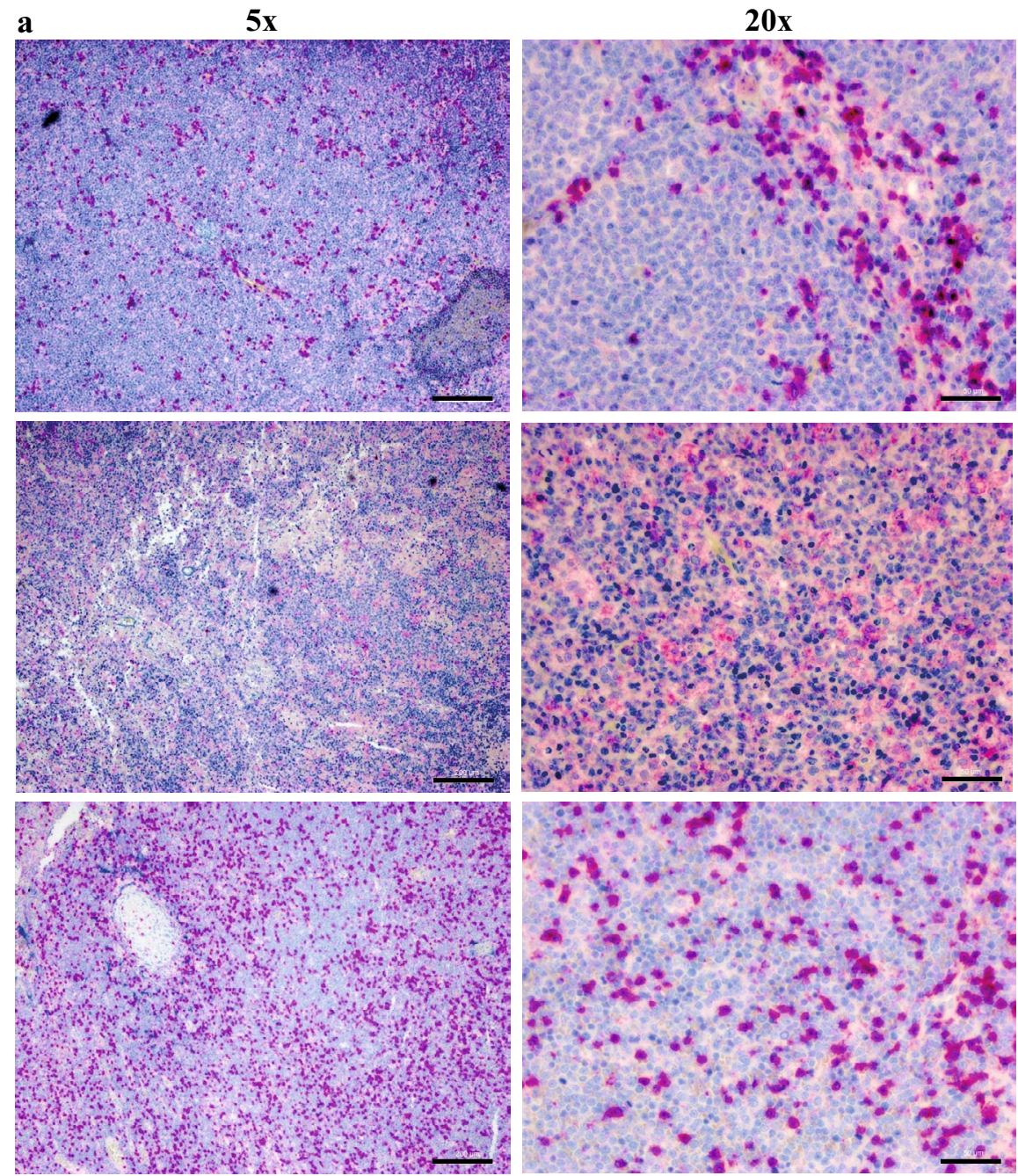

CD3



CD4

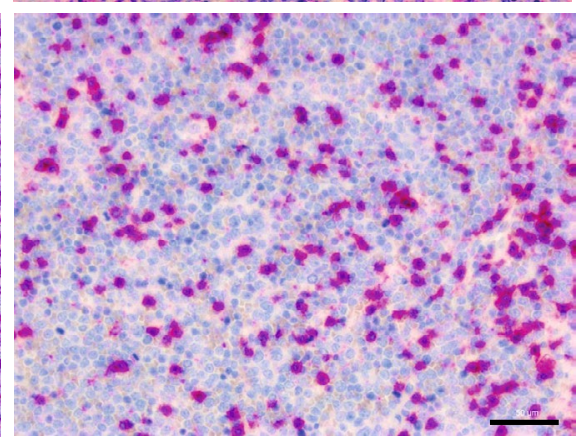

CD8 b

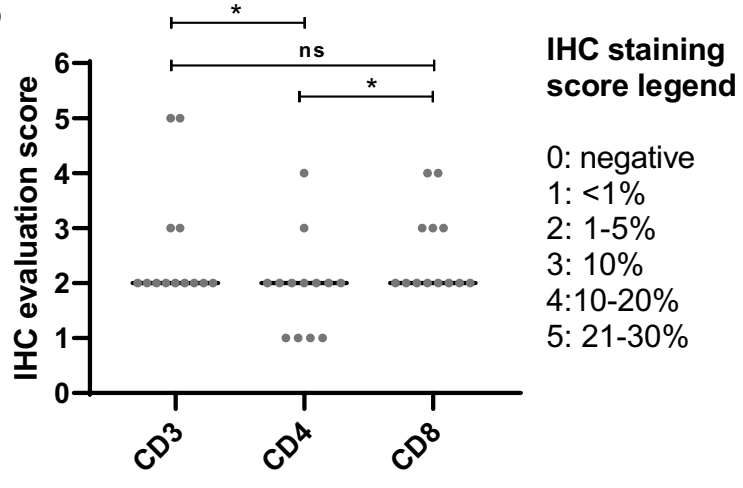


Fig. 2 Effect of CD4 + T cells on LCL proliferation, cell cycle and viability. LCLs were cultured for 9 days either alone or in co-culture at various ratios with expanded autologous $\mathrm{CD} 4+\mathrm{T}$ cells activated using anti-CD3/CD28 beads. At given times cells were harvested, stained and analyzed using flow cytometry. LCLs were pre-gated based on CD19 expression.

Shown are mean \pm SD of mean percentage of positive cells from 3 TMC donors a Mean percentage of EdU + LCLs was measured using Click-iT Flow Cytometry kit. $p$ values were calculated using two-way ANOVA with Sidak's test for multiple comparisons. $p>0.05$ not significant (n.s.) b Mean percentage of LCLs in different cell cycle stages was measured using EdU Click-iT Flow cytometry kit and FxCycle dye. c Mean percentage of dead, apoptotic and living LCLs was measured using Annexin V stain and Zombie Viability stain.

d Histogram overlay used for gating on EdU + and EdU- cells from one representative donor. $\mathbf{e}$ Pseudocolor plot used for gating on cells in G1, G2 and S phases of cell cycle for cell cycle assay from one representative donor. $\mathbf{f}$ Pseudocolor plot used for gating on living, apoptotic and dead cells for apoptosis assay from one representative donor

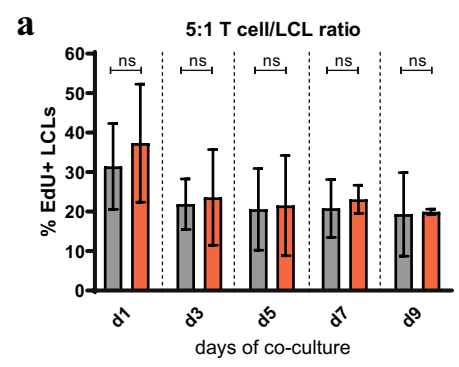

EdU proliferation assay

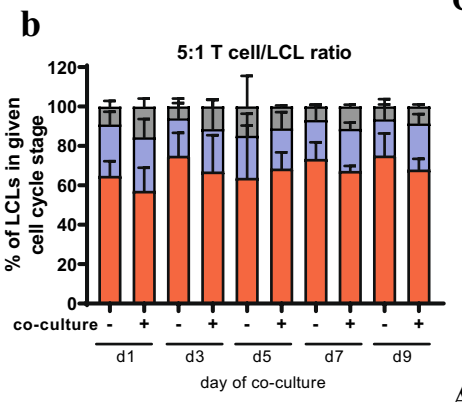

Cell cycle assay

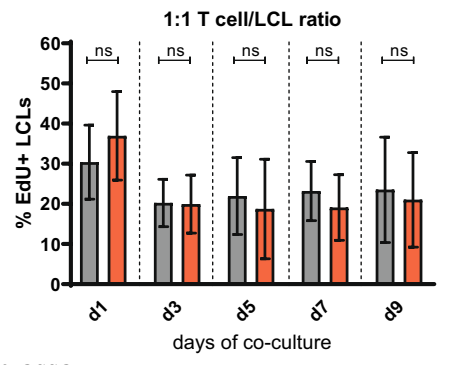

$\square$ LCLs (alone)

$\square$ LCLs (co-culture)

c
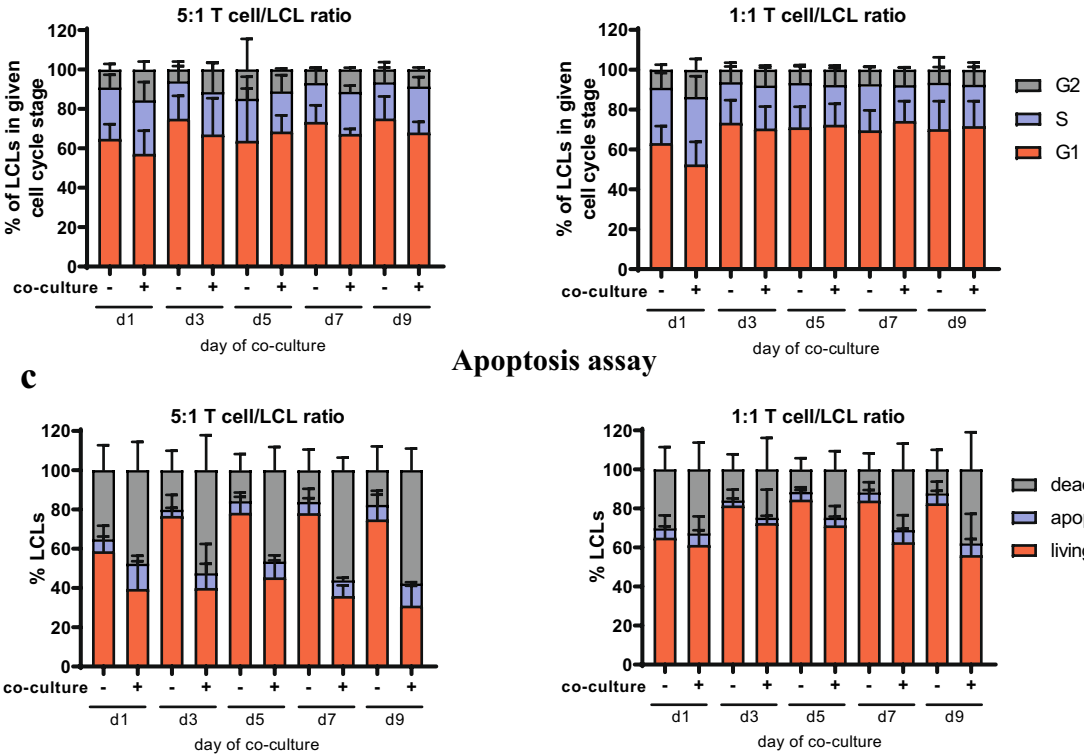

d



e

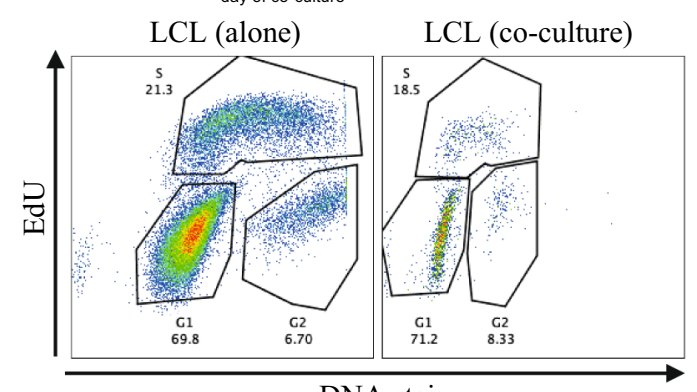

f

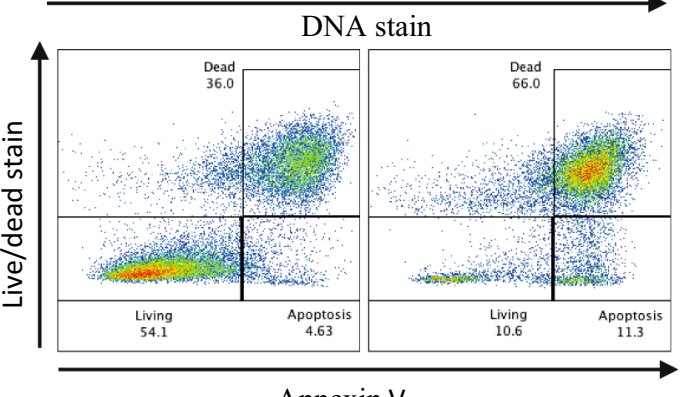

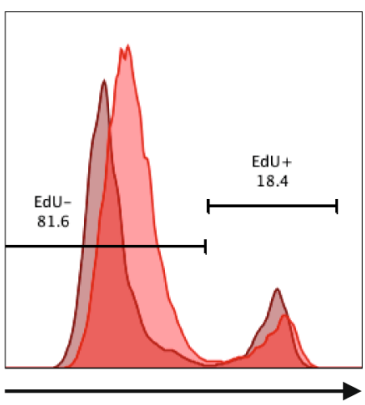

EdU

LCLs (alone)

LCLs (co-culture)

Annexin V

a high proportion of Th1 cells (T-bet + , IFN $\gamma+$ ), but no Th2 cells (GATA $3+$, IL-13+) or Tfh cells (bcl6 +, IL-21 +) by flow cytometry (Fig. 4e, 4f, Supplementary Figure S2c). Furthermore, we detected IL-21 and IL-13 on mRNA level (Fig. 4h), but no intracellular protein by flow cytometry (Fig. 4e, 4f). IFN $\gamma$, in contrast, was highly expressed at both mRNA and protein level.

Collectively, these data suggest that CD4 $+\mathrm{T}$ cells in co-culture are predominantly of Th1 phenotype and that 
Fig. 3 Effect of CD4 + T cells on LCL EBV Latency stage and EBV gene expression. LCLs were cultured for 7 days either alone or in co-culture at various ratios with expanded autologous $\mathrm{CD} 4+\mathrm{T}$ cells activated using anti-CD3/CD28 beads. At given time points, cells were harvested and LCLs were isolated using CD19+ beads and autoMACS. Different symbols represent different conditions, while different colors represent different TMC donors. $p$ values were calculated using two-way ANOVA with Sidak's test for multiple comparisons. $p>0.05$ not significant (n.s.), $p<0.1^{*}$, $p<0.01 * *, p<0.001 * * *$. WB images used for quantification can be found in Supplementary Fig. 1. a EBNA2 and $L M P 1$ expression at 5:1 T cell/ LCL ratio was determined using qRT-PCR. Shown are mean $\pm \mathrm{SD}$ of $\mathrm{dCt}$ values normalized to geometric means of TBP and YWHAZ. b Total $E B N A 2$ protein expression was assessed using Western blotting. Western blot image was quantified and normalized to $\beta$-actin as loading control. Shown are mean $\pm \mathrm{SD}$ of normalized volume of EBNA2 band. c Cp and Qp promoter usage at 5:1 $\mathrm{T}$ cell/LCL ratio was determined using qRT-PCR. Shown are mean $\pm \mathrm{SD}$ of $\mathrm{dCt}$ values normalized to geometric means of TBP and YWHAZ. d Total $L M P 1$ protein expression was assessed using Western blotting. Western blot image was quantified and normalized to $\beta$-actin as loading control. Shown are mean $\pm \mathrm{SD}$ of normalized volume of $L M P 1$ band a


EBNA2 protein
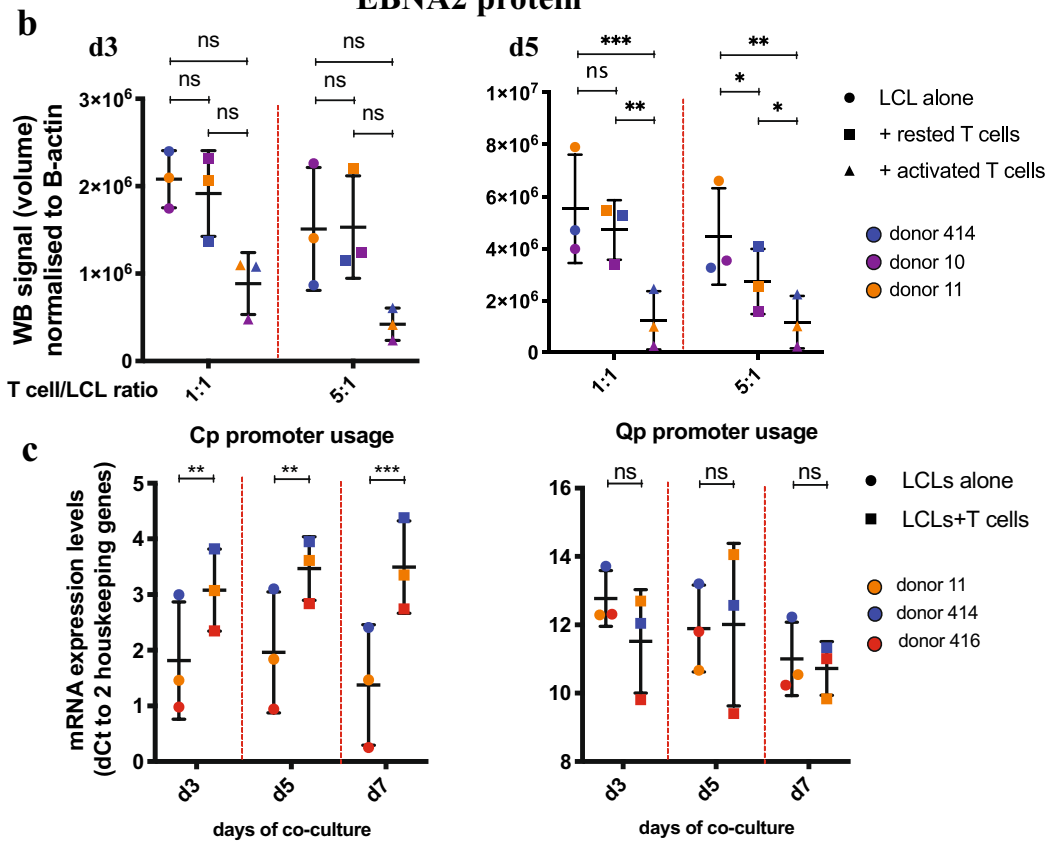

Qp promoter usage

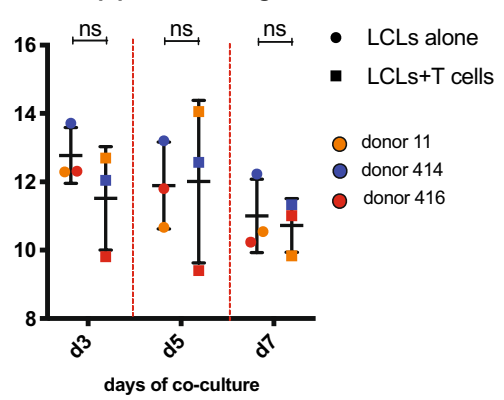

LMP1 protein

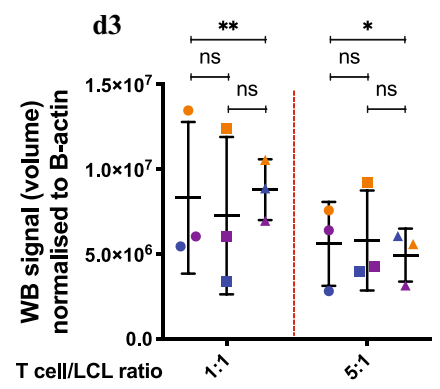

IFN $\gamma$ and CD40L are likely to be involved in CD4 + T-cellmediated changes in LCL phenotype.

\section{Establishment and validation of a novel model of $\mathrm{IgH} / \mathrm{c}-\mathrm{myc}$ translocation and knock-in of a GFP tag in pre-BL cells using CRISPR/CAS9}

In order to mechanistically test whether suppression of the EBV Latency III by CD $4+\mathrm{T}$ cells allows pre-eBL cells with eBL-associated genetic abnormalities to switch to the Latency I program, we modeled the main eBL-associated genetic abnormality, i.e., the $\mathrm{IgH} / \mathrm{c}$ - $m y \mathrm{c}$ translocation. For this, we generated LCLs from four healthy donors with and without $I g H / c-m y c$ translocation using CRISPR/CAS9 technology. To facilitate selection of rare $I g H / c-m y c+$ cells, we introduced a CMV-driven GFP tag into the reciprocal translocation breakpoint (Fig. 5a).

First, we designed and validated gRNAs capable of introducing dsDNA breakpoints into relevant $c$-myc and IgH regions, selecting the most efficient gRNAs using Surveyor assay (Supplementary Fig. 3). Next, we tested whether the introduction of simultaneous dsDNA breaks in $c-m y c$ 
a

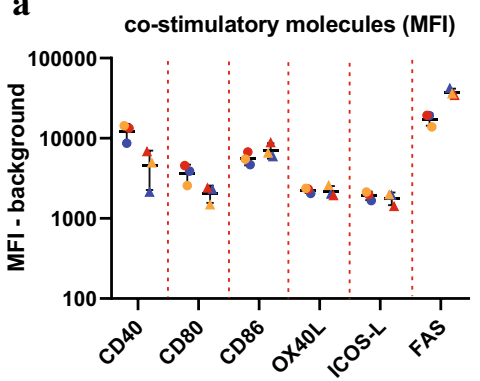

c

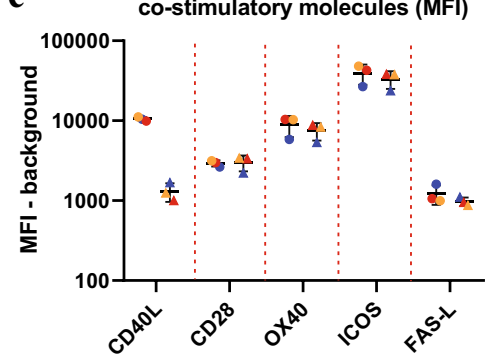

e cytokines/TFs (MFI)

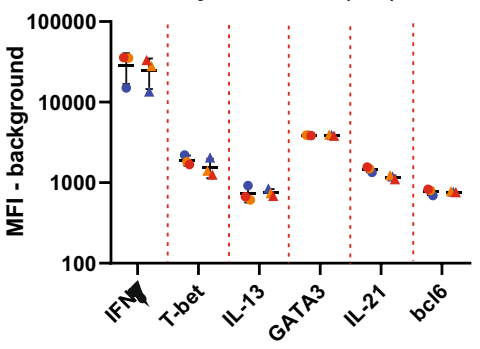

g

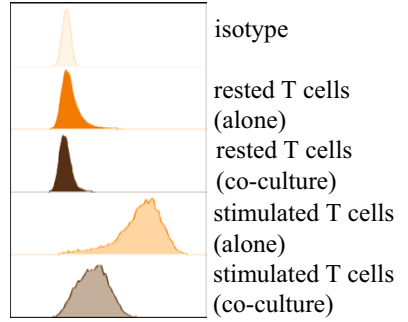

b

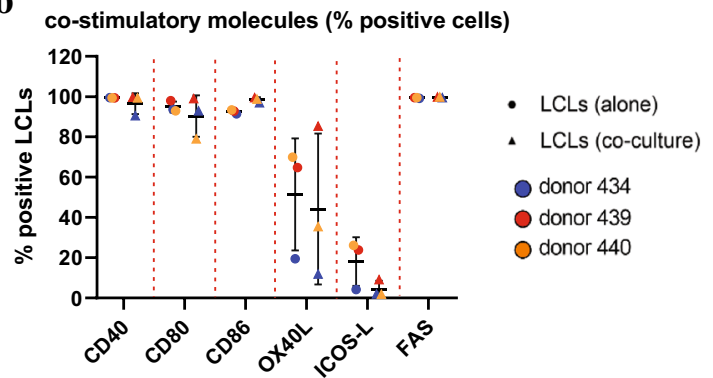

d

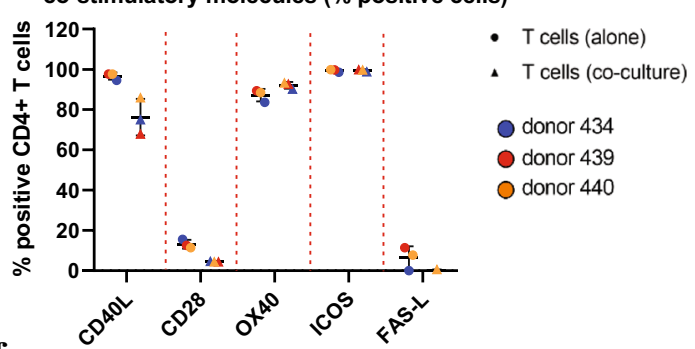

f

cytokines/TFs (\% positive cells)

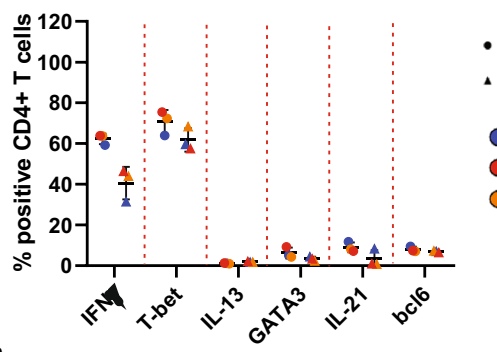

h

cytokines/TFs CD4+ $T$ cells

(RT-qPCR)

T cells (alone)

- T cells (co-culture)

donor 434

donor 439

O donor 440
Fig. 4 Expression of co-stimulatory molecules and T helper subsetassociated markers in in vitro T cell-LCL co-culture system. LCLs were cultured either alone or in co-culture with 1:3 LCL/T cell ratio of expanded autologous CD4 $+\mathrm{T}$ cells activated using anti-CD3/ CD28 beads. CD4 + T cells were cultured alone either activated with beads or rested as a control. After 5 days of co-culture, cells were harvested, stained and analyzed using flow cytometer. LCLs were pre-gated based on CD19 expression. T cells were pre-gated based on CD4 expression. Isotype staining was used to determine positive cells. Shown are mean \pm SD of either mean fluorescent intensity (MFI) or percentage of positive cells. Different symbols represent different conditions, while different colors represent different TMC donors. Histogram overlays for one representative donor can be found in Supplementary Fig. 2. a, b Mean fluorescent intensity (MFI) (a) and percentage of positive cells (b) for expression of surface co-stimulatory molecules on LCLs. c, d Mean fluorescent intensity (MFI) (c) and percentage of positive cells (d) for expression of surface co-stimulatory molecules on $\mathrm{CD} 4+\mathrm{T}$ cells. e, $\mathbf{f}$ Mean fluorescent intensity (MFI) (e) and percentage of positive cells (f) for cytokine production and transcription factor expression in $\mathrm{CD} 4+\mathrm{T}$ cells. g. Histogram overlay for CD40L expression for one representative donor. $\mathbf{h}$ After 5 days of co-culture, CD4 + T cells were isolated by negative selection using CD19+ beads and autoMACS. Gene expression was determined using qRT-PCR. Shown are mean \pm SD of dCT values normalized to geometric means of $P O L 2 A, U B C$ and $T B P$ 
a
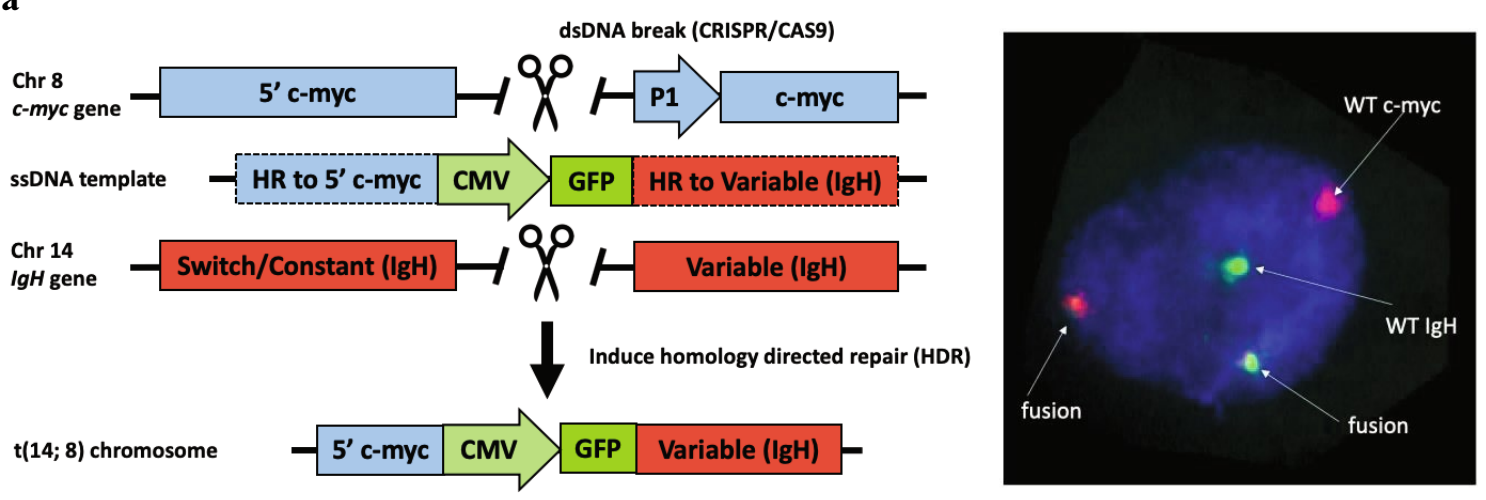

b

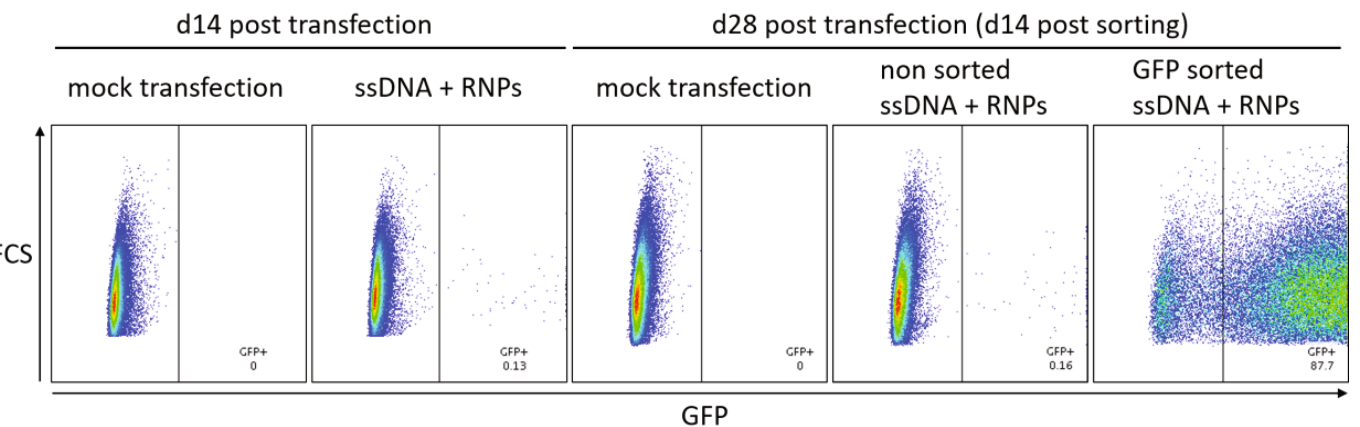

c
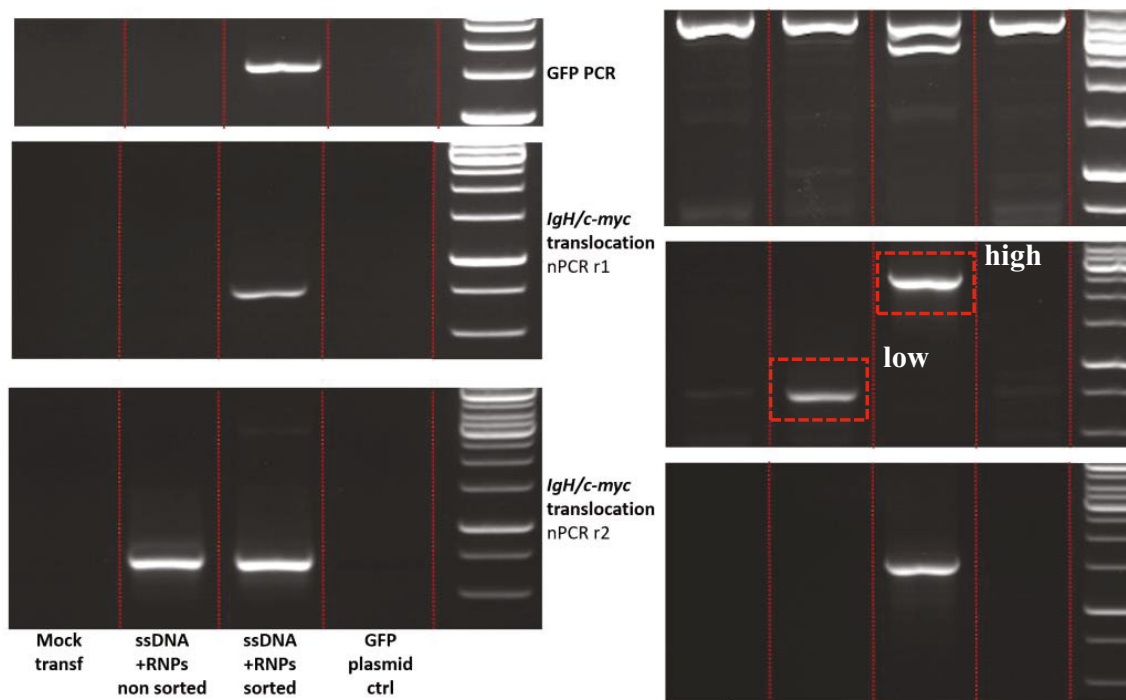

reciprocal translocation nPCR r1 2551bp (GFP insert)
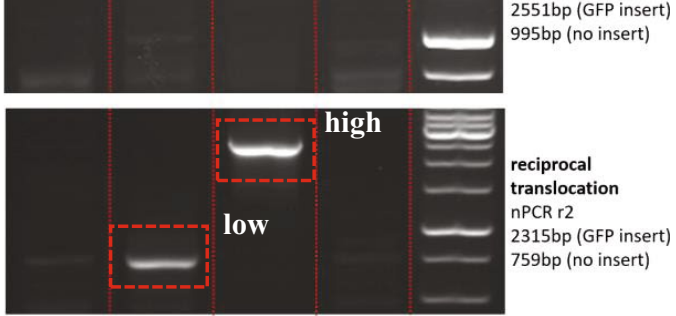

d

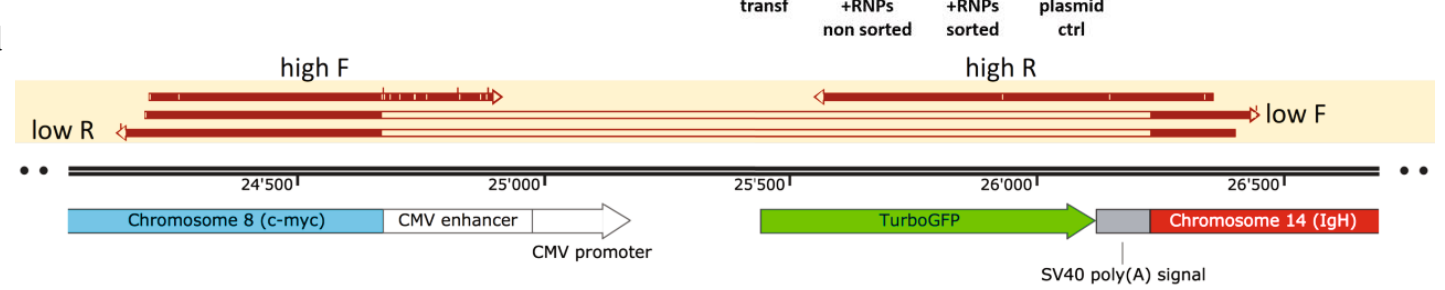

Fig. 5 Generation and validation of $I g H / c-m y c+L C L s$. a Overall experimental setup for generation of $I g H / c-m y c+$ LCLs. b-e LCL line was electroporated with $I g H / c-m y c$ targeting CAS9 RNPs and with ssDNA template containing the CMV-GFP insert. Cells were outgrown for 14 days, and then GFP + cells were sorted using FACS. GFP signal and presence of the translocations of interest were assessed using flow cytometry (b) and nested PCR (c). Highlighted PCR bands from nPCR assay were sequenced to confirm identity of the bands (d). Presence of $I g H / c-m y c$ translocation was confirmed by dual-probe FISH (e). Repeats performed on additional donors can be found in Supplementary Fig. 5 
and $I g H$ regions resulted in $I g H / c-m y c$ translocation. We confirmed the presence of translocations by gDNA PCR (Supplementary Fig. 4). Then, we generated and validated a ssDNA insert, designed to integrate a CMV + GFP tag into the reciprocal translocation (Fig. 5a, Supplementary Fig. 5). Next, we generated and sorted $I g H / c-m y c+$ LCLs with GFP expressed from the insert in the reciprocal translocation breakpoint (Fig. 5b) and confirmed the presence of translocation by gDNA PCR (Fig. 5c) by sequencing (Fig. 5d), as well as by FISH (Fig. 5e, Supplementary Fig. 6).

Finally, we tested if the presence of the translocation alone has any effect on the LCL phenotype and assessed differences in proliferation (Fig. 6a), viability (Fig. 6b) and cell cycle distribution (Fig. 6c) of IgH/c-myc + LCLs as compared to WT LCLs. We could not detect any significant differences between WT and IgH/c-myc + LCLs in RNA (Figure S8a, Fig. 6e) and protein (Fig. 6d, Supplementary Fig. 7) levels of any of the eBL/EBV growth program markers tested nor on $\mathrm{Cp} / \mathrm{Qp}$ promoter usage (Fig. 6f). Furthermore, we did not observe any effect of translocation alone on expression of co-stimulatory molecules, involved in $\mathrm{T}$ cell/LCL interaction (Fig. 6g, Supplementary Figure S8b) or on expression of surface markers, commonly associated with EBV or eBL phenotype (Fig. 6h, Supplementary Figure S8c).

Overall, our observations are in line with the established premise that the translocation alone is not sufficient for $\mathrm{eBL}$ development.

\section{IgH/c-myc + pre-eBL cells do not escape viability suppression by CD4 + T cells}

Next, we used our translocation model to test whether $\mathrm{IgH} / \mathrm{c}$ $m y c+$ LCLs survive the interaction with CD4 + T cells better than WT LCLs. Thus, we cultured parental WT and offspring $I g H / c-m y c+$ LCLs in the presence of CD $4+\mathrm{T}$ cells and assessed changes in proliferation, viability and $\mathrm{mRNA}$ /protein levels of several crucial eBL and EBV markers. While $\mathrm{CD} 4+\mathrm{T}$ cells outgrew both WT and IgH/c-myc + LCLs, they tended to outgrow $\mathrm{IgH} / \mathrm{c}-\mathrm{myc}+\mathrm{LCLs}$ faster than WT LCLs at both 5:1 (Fig. 7a) and 1:1 E/T ratio (Supplementary Fig. 8). At a 5:1 ratio, CD4+T cells suppressed the viability of WT and $I g H / c-m y c+$ LCLs to a similar extent, while at a 1:1 ratio, $\mathrm{CD} 4+\mathrm{T}$ cells had a stronger negative effect on viability of $I g H / c-m y c+$ LCLs as compared to WT LCLs (Fig. 7b). Thus, CD $4+\mathrm{T}$ cells affected IgH/c-myc + LCLs at both a "low dose" and "high dose" E/T ratio, while the viability of WT cells was strongly reduced only at "high dose" ratio. Notably, we could also see a reduced percentage of GFP + cells among living cells in co-culture, which was more profound at 5:1 E/T ratio (Fig. 7c). There were no effects of CD4 + T cells on LCL proliferation (Fig. 7d, Supplementary Fig. 8) in co-culture or cell cycle distribution
(Supplementary Fig. 8), neither on $I g H / c-m y c+$ LCLs nor on WT LCLs. Finally, there was no difference in CD4 + T cell effect on WT LCLs and $I g H / c-m y c+$ LCLs in expression of any EBV gene (EBNA2, LMP1, Cp or Qp promoter usage) or eBL markers (c-myc and bcl6) measured (Fig. 8).

Overall, our data imply that $I g H / c-m y c+$ LCLs are more susceptible to CD4 + T-cell-induced suppression of viability than WT LCLs.

\section{Discussion}

Evidence accumulates that $\mathrm{CD} 4+\mathrm{T}$ cells are involved in the multi-step development of eBL, but the pathogenic role of $\mathrm{CD} 4+\mathrm{T}$ cells remains enigmatic. Here, we unprecedently show that $\mathrm{CD} 4+\mathrm{T}$ cells are present in primary eBL tumor tissues and that $\mathrm{CD} 4+\mathrm{T}$ cells on the one hand kill pre-eBL cells in vitro and on the other hand can initiate crucial EBV Latency III to Latency I switch, which supposedly takes place early in eBL development, supporting the survival of EBV-infected pre-eBL cells by lowering their immune recognition. Furthermore, while we show that the mere presence of the characteristic $\mathrm{IgH} / \mathrm{c}-\mathrm{myc}$ translocation does not suffice to escape CD4 + T-cell-mediated killing in vitro, the CD4 + T-cell-mediated suppression of the Latency III program in vivo may allow cells harboring the $I g H / c-m y c$ translocation and additional mutations, to evade immune suppression and eventually proliferate by means of deregulated $c-m y c$ activity, resulting in neoplasia.

A key finding of our study is the first-time demonstration of the presence of $\mathrm{CD} 4+\mathrm{T}$ cells in primary eBL tissue. They may either have been present at the emergence and propagation of the eBL cells or have infiltrated the neoplastic cells after having been attracted by antigen, or both. Since CD $4+\mathrm{T}$ cells, depending on their subpopulation nature, exert either helping or suppressing/cytotoxic functions, their impact on eBL cells or their precursors may be dichotomous as well.

Another key finding of our study is the demonstration that polyclonal activated CD4 $+\mathrm{T}$ cells suppress the viability and thereby the outgrowth of autologous pre-eBL cells. Reduced viability is further confirmed by reduction in the percentage of GFP + LCLs upon co-culture with CD4 + T cells, as GFP signal is downregulated in dying cells [39]. The exact mode of LCL cell death in our co-culture system is unclear. We did not observe changes in the relative proportion of apoptotic cells over time, suggesting that alternative cell death pathways might be involved. CD4 + T-cells-mediated loss of EBNA2 expression in LCLs offers alternative explanation, as EBNA2 confers anti-apoptotic functions and its loss was shown to reduce the viability of LCLs [40]. These data indicate that CD4 $+\mathrm{T}$ cells can exhibit suppressive or cytotoxic functions, in agreement with previous reports [26-29]. 


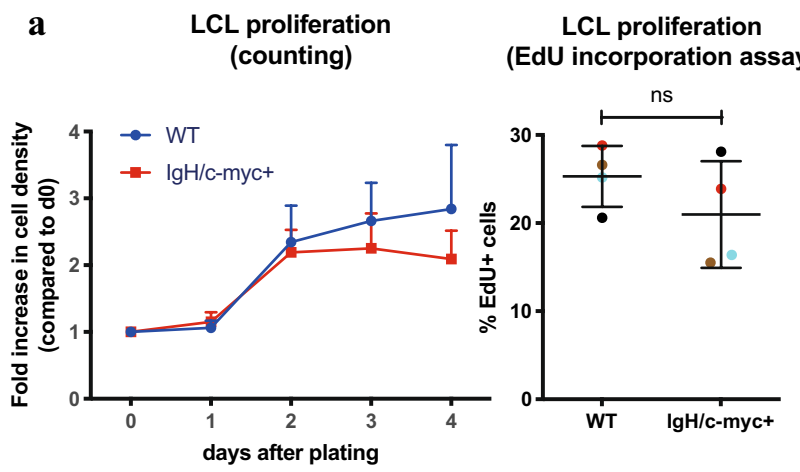

b LCL viability

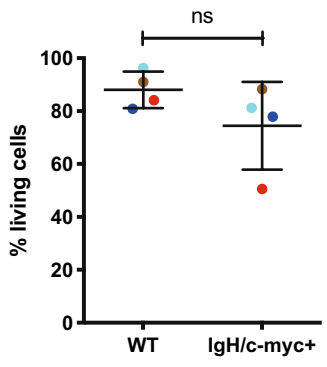

C Cell cycle analysis

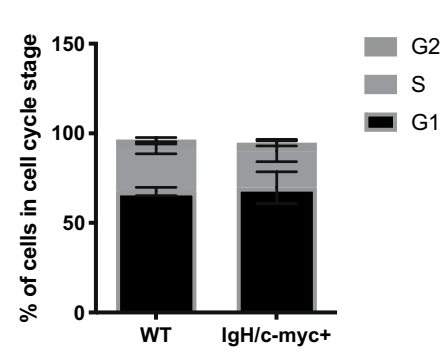

G2 G1

d

EBNA2 protein
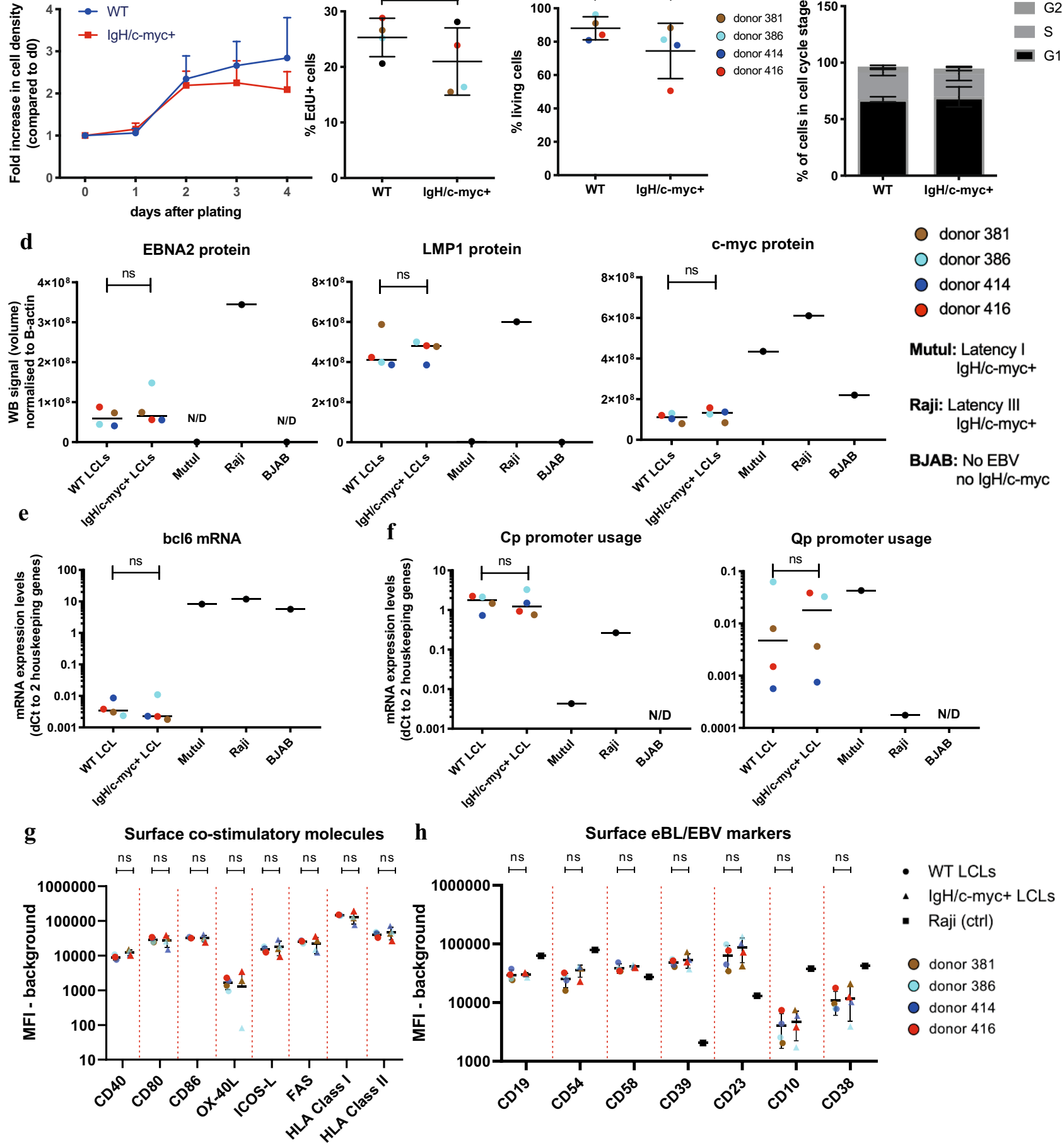

A third key finding in this study is our demonstration that $\mathrm{CD} 4+\mathrm{T}$ cells can promote eBL emergence indirectly by inducing a switch to a more eBL-like phenotype in autologous EBV-infected pre-eBL cells resulting in immune escape. This is achieved, at least in part, through changes in expression of EBNA2, a transcription factor crucial for
Latency III program, and $b c l 6$, a key marker of eBL. Specifically, we show CD4+T-cell-mediated reduction in the Cp promoter usage in LCLs and a consecutive reduction in EBNA2 expression, resulting in switching away from the dominant EBV Latency III program. As we did not see a reduction in LMP1 levels, the switch to Latency I program 
4Fig. 6 Effect of $I g H / c-m y c$ translocation on LCL phenotype. LCLs from four donors either with or without $\mathrm{IgH} / \mathrm{c}-\mathrm{myc}$ translocation were cultured at same density for 3 days and compared to assess the effect of translocation on LCL phenotype. Different symbols represent different conditions, while different colors represent different TMC donors. $p$ values were calculated using paired t test. $p>0.05$ not significant (n.s.). For flow cytometry experiments, isotype staining was used to determine positive cells. Histogram overlays for one representative donor can be found in Supplementary Fig. 8. WB images used for quantification can be found in Supplementary Fig. 6. a Proliferation of LCLs was assessed by counting daily with hemocytometer and by EdU incorporation assay using EdU Click-iT Flow Cytometry Kit. b LCL viability was assessed using Zombie viability dye. c) Percentage of LCLs in different cell cycle stages was measured using EdU Click-iT Flow Cytometry Kit and FxCycle dye. d Total protein expression was assessed using Western blotting. Western blot image was quantified and normalized to $\beta$-actin as loading control. Shown are mean \pm SD of normalized volume of corresponding band. e-f Gene expression was determined using qRT-PCR. Shown are mean $\pm \mathrm{SD}$ of dCt values normalized to geometric means of $T B P$ and $Y W H A Z$. g, d Expression of surface co-stimulatory molecules (g) and EBV/eBL-associated markers (h) was assessed using flow cytometer. Shown are mean \pm SD of mean fluorescent intensity (MFI)

in our in vitro system was incomplete. This can be explained by lack of Tfh cells in our system, which can induce LMP1 suppression in LCLs via production of IL-21 [32]. Therefore, it is possible that during autologous CD4 + T cells/ pre-eBL cell interaction in vivo, in the presence of Tfh and IL-21, full Latency III to Latency I switch does take place. Furthermore, CD4 + T cells in our co-culture are activated using polyclonal anti-CD3/CD28 beads, rendering the effect of CD4 + T cells on LCLs independent on expression of HLA Class II molecules. As EBV latency [41] and $c$-myc activity [42] are known to affect expression of HLA Class II molecules on B cells, it is possible that the in vivo effect of relatively rare EBV-specific $\mathrm{CD} 4+\mathrm{T}$ cells would differ from the effect observed in our in vitro system. On the other hand, polyclonal expansion mimics the effect of non-specifically chronically stimulated CD4 + T cells, found in eBLassociated chronic malaria [37], and obviates outgrowing EBV-specific CD4 + T cells lines, which would artificially skew the phenotype and antigen specificity of CD4 $+\mathrm{T}$ cell pool in our in vitro system.

While CD4 + T cells suppress outgrowth of "wildtype" EBV-infected B cells, we needed to consider the possibility of rare EBV-infected B cells with $\mathrm{IgH} / \mathrm{c}$-myc translocation interacting with $\mathrm{CD} 4+\mathrm{T}$ cells. Indeed, we hypothesized that EBV-infected B cells with $I g H / c-m y c$ translocation could switch to the alternative growth program and survive the interaction with CD $4+\mathrm{T}$ cells better than wild-type EBV-infected B cells. Therefore, we established a novel $\mathrm{IgH} / \mathrm{c}-\mathrm{myc}$ translocation model. It offers a number of advantages over existing models relying on either $c$-myc overexpression or stable transfection with $c$-myc/IgH-containing plasmids [24, 25]. Firstly, we induce the translocation between endogenous $c$-myc and
IgH genes, rather than another copy of the $c$-myc gene. Secondly, the existing epigenetic landscape is maintained. Thirdly, all relevant enhancers/regulators remain in place and at physiological distance from the $c$-myc gene. Finally, by placing the GFP tag into reciprocal translocation breakpoint, rather than into the $I g H / c-m y c$ translocation of interest, we avoid introducing a strong promoter into the vicinity of the $c-m y c$ gene. Notably, the introduction of $\mathrm{IgH} / \mathrm{c}-\mathrm{myc}$ translocation did not induce significant changes in LCL cell phenotype, considered as surrogate for preeBL. This is not surprising, as the literature suggests that EBV Latency III program is dominant over $c$-myc growthprogram [24, 25].

Our final key observation is that the mere presence of IgH/c-myc translocation does not protect autologous EBVinfected B cells from CD4 + T-cell-mediated killing, but rather makes them more susceptible to it. This could be explained by the fact that $I g H / c-m y c+$ LCLs have a higher capacity for $c-m y c$ expression due to the presence of the translocation. In the absence of CD4 $+\mathrm{T}$ cells, EBNA2 would maintain a moderate level of $c$-myc expression [20, 43], suppress excessive $c$-myc expression from $\mathrm{IgH} / \mathrm{c}-\mathrm{myc}$ translocation [44] and provide some protection from $c$-mycmediated apoptosis [40] in both WT and $I g H / c-m y c+$ LCLs. In the presence of $\mathrm{CD} 4+\mathrm{T}$ cells, which suppress EBNA2 in LCLs, $I g H / c-m y c+$ LCLs become much more susceptible to apoptosis, as compared to WT LCLs, due to their capacity to express higher levels of $c$-myc from the translocated chromosome. Cells that express high levels of $c$-myc would die before the mRNA analysis, which may explain the observed lack of changes in $c$-myc levels in $\mathrm{IgH} / \mathrm{c}$ $m y c+$ LCLs in the presence of CD $4+\mathrm{T}$ cells. Furthermore, LCLs already express high levels of $c$-myc and even small, undetectable changes in $c$-myc levels, may have strong physiological effect [45]. Fully established eBL cells, in contrast, harbor additional mutations, such as ID3 and GNA13 [5], which may protect them from $c$-myc overexpression-induced apoptosis, while allowing the benefit from $c$-myc-mediated enhancement of proliferation. Several clones of EBNA2inducible/c-myc-inducible cell line were shown to survive and proliferate in a $c$-myc-dependent manner in the absence of EBNA2 after a several-week-long lag in proliferation [25], further supporting our hypothesis.

In conclusion, $\mathrm{CD} 4+\mathrm{T}$ cells in eBL likely contribute to eBL pathogenesis by exhibiting a dichotomous impact through initiation of EBV Latency III to Latency I switch, thereby reducing EBV-infected B cell survival on the one hand, but increasing their survival by reducing their recognition as EBV-infected by immune cells, possibly followed by outgrowth of $\mathrm{IgH} / \mathrm{c}$ - $m y \mathrm{c}$-translocated cells on the other hand. Our model of B cells harboring the $I g H / c-m y c$ translocation will be instrumental for further studies on eBL pathogenesis. Since the method of its generation can easily 
$\mathbf{a}$

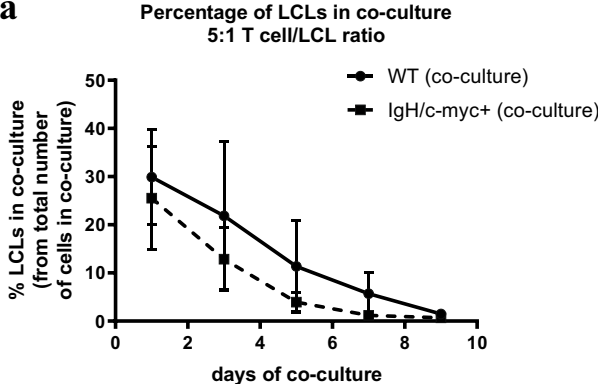

b

Apoptosis assay

5:1 T cell/LCL ratio d EdU proliferation assay

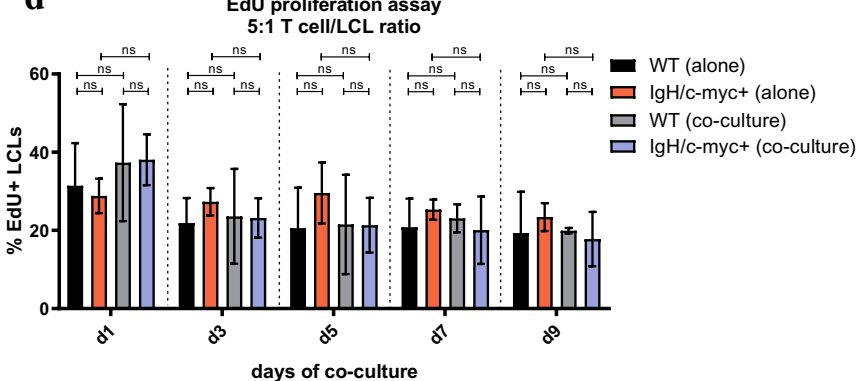

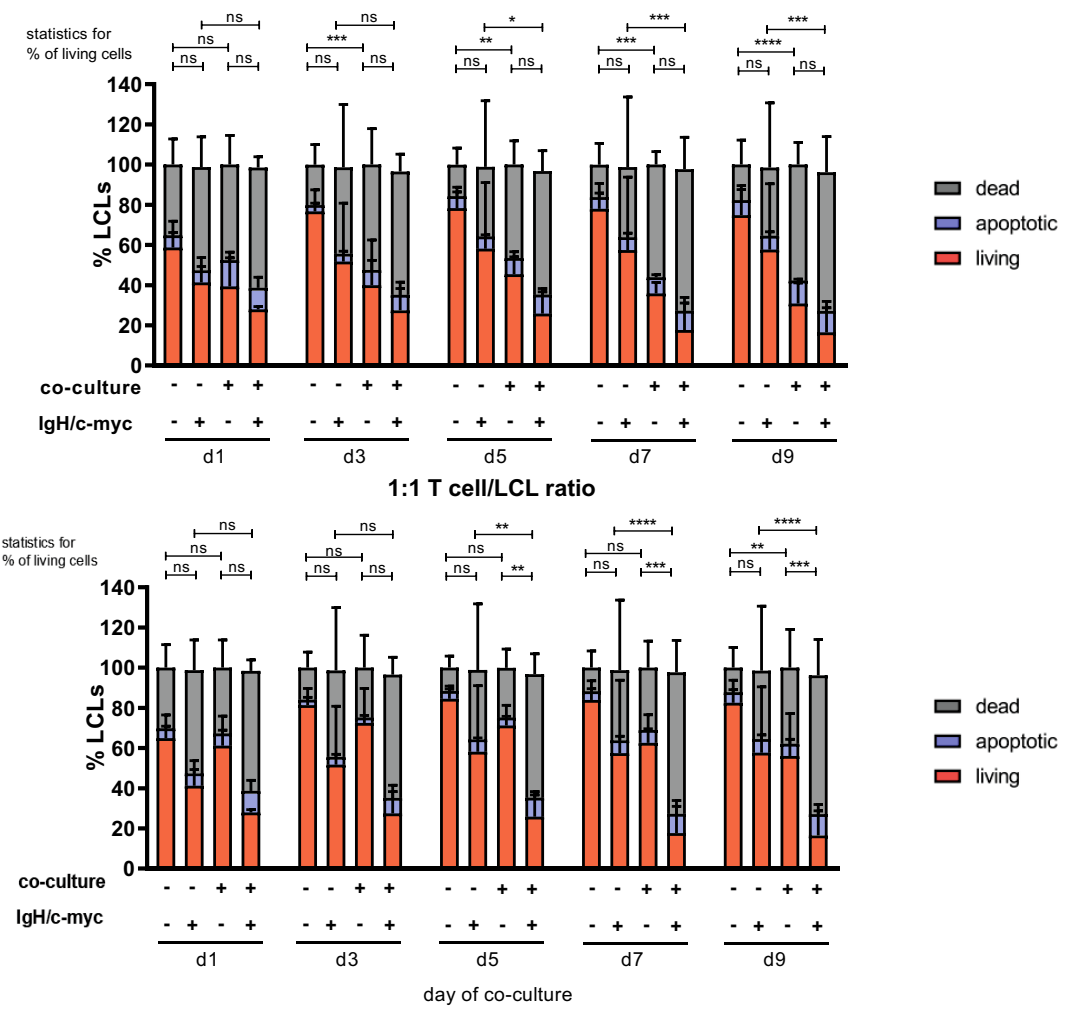

c

Percentage of GFP+ LCLs

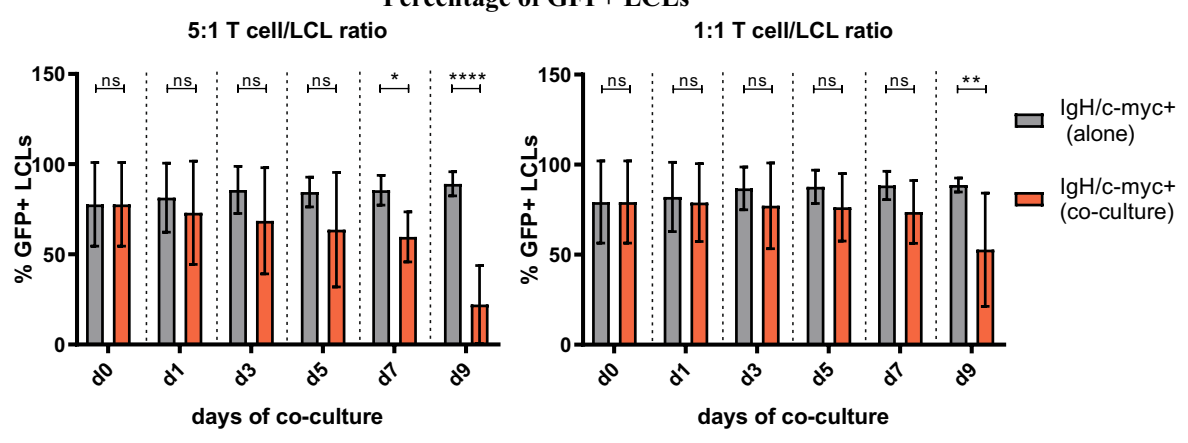

Fig. 7 Effect of $\mathrm{CD} 4+\mathrm{T}$ cells on proliferation and viability of $\mathrm{IgH} /$ $c-m y c+$ LCLs LCLs either with or without $\mathrm{IgH} / c-m y c$ translocation were cultured for 9 days either alone or in co-culture with various ratios of expanded autologous $\mathrm{CD} 4+\mathrm{T}$ cells activated using antiCD3/CD28 beads. At given time points, cells were harvested, stained and analyzed using flow cytometer. LCLs were pre-gated based on CD19 expression. Shown are mean \pm SD of mean percentage of positive cells from three TMC donors. $p$ values were calculated using two-way ANOVA with Tukey's test for multiple comparisons. $p>0.05$ not significant (n.s.), $p<0.1^{*}, p<0.01^{* *}, p<0.001^{* * *}$, $p<0.0001 * * * *$. Repeats with $1: 1 \mathrm{~T}$ cell/LCL ratios can be found in Supplementary Fig. 7. a Mean percentage of LCLs in co-culture was determined by CD19 and CD4 staining. b Mean percentage of dead, apoptotic and living LCLs was measured using Annexin V stain and Zombie Viability stain. c Mean percentage of GFP+LCLs. d Mean percentage of EdU + LCLs was measured using Click-iT Flow Cytometry Kit 
a
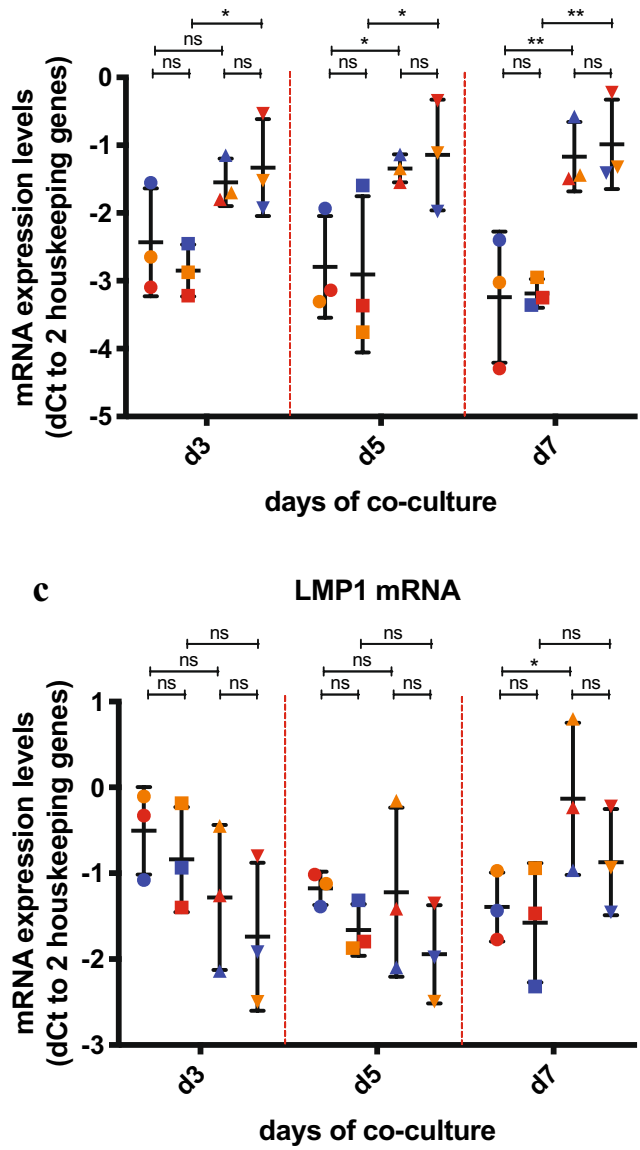

e

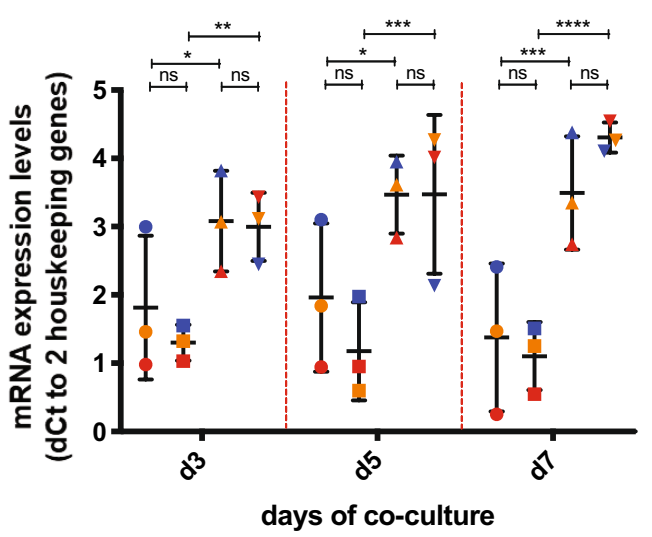

b

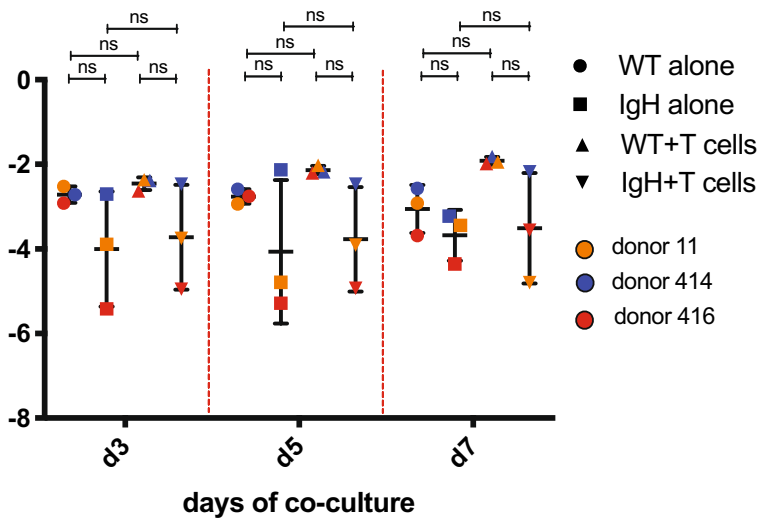

d

bcl6 mRNA

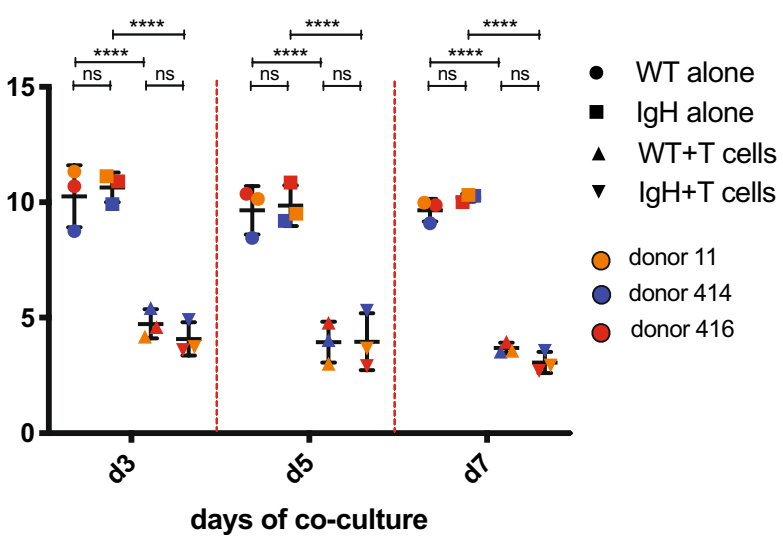

f

Qp promoter usage

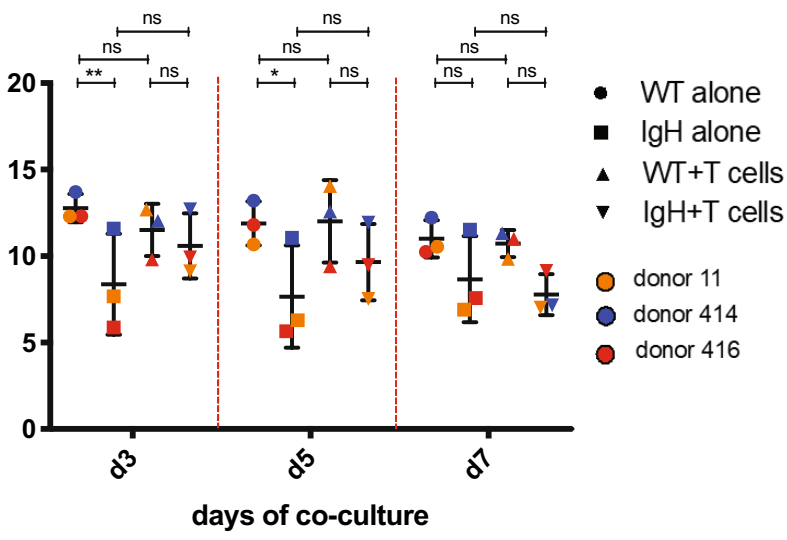

Fig. 8 Effect of $\mathrm{CD} 4+\mathrm{T}$ cells on gene expression in $\mathrm{IgH} / \mathrm{c}$ $m y c+$ LCLs. LCLs either with or without $I g H / c-m y c$ translocation were cultured for 7 days either alone or in co-culture with various ratios of expanded autologous $\mathrm{CD} 4+\mathrm{T}$ cells activated using anti-CD3/CD28 beads. At given time points, cells were harvested and LCLs were isolated using CD19+beads and autoMACS. Gene

expression was determined using qRT-PCR. Shown are mean \pm SD of $\mathrm{dCt}$ values normalized to geometric means of TBP and $Y W H A Z$. Different symbols represent different conditions, while different colors represent different TMC donors. $p$ values were calculated using twoway ANOVA with Tukey's test for multiple comparisons. $p>0.05$ not significant (n.s.), $p<0.1^{*}, p<0.01^{* *}, p<0.001^{* * *}, p<0.0001^{* * * *}$ 
be applied to engineer other clinically relevant translocations, it may thus serve to delineate novel therapies.

Supplementary Information The online version contains supplementary material available at https://doi.org/10.1007/s00262-021-03057-5.

Acknowledgements We thank the pediatric patients and donors who provided the clinical samples. We thank the Division of Otolaryngology at University Children's Hospital of Zurich for providing us with tonsils after routine tonsillectomy. We thank the Cytogenetics and Cytogenomics Oncology Laboratory at University Children's Hospital of Zurich for technical help when establishing FISH assay for $\mathrm{IgH} / \mathrm{c}$ $m y c$ translocation. We thank Prof. Micah Luftig from Duke University, USA, for providing us with B95-8-ZHT strain that we used for EBV particle production.

Author contribution SS designed the project, designed, executed and analyzed the experiments, and drafted the manuscript. LF, KS and SB performed and analyzed the experiments. TA, ST, CB and FKN provided the resources. $\mathrm{MB}$ provided the resources and proofread the manuscript. WK and $\mathrm{AB}$ provided the resources, performed immunohistochemistry and analyzed the immunohistochemistry data. SP and YP provided eBL cases, performed immunohistochemistry and proofread the manuscript. DN provided resources, supervised the research and contributed to writing the manuscript. SB contributed to project design, provided resources, supervised the research and contributed to writing the manuscript.

Funding Open Access funding provided by Universität Zürich. This work was supported by the Krebsliga Schweiz/Swiss Cancer League (grant number KFS-3958-08-2016-R, DN) and by the Children's Research Center (CRC) of the University Children's Hospital Zurich (DN and SB).

\section{Declarations}

Conflict of interest The authors declare that they have no conflict of interest.

Ethical approval The study was performed in accordance with the 1964 Declaration of Helsinki. The use of paraffin tissue recuts from eBL patients and palatine tonsils from children undergoing routine tonsillectomy was approved by the regional ethics committee (University of the Witwatersrand, Johannesburg, South Africa, Nr. M180294 and Kantonale Ethikkommission Zürich, KEK-ZH Nr. StV 40/05, respectively).

Consent to participate The patients and the parents or guardians of tonsillectomy subjects gave informed consent for use of samples.

Open Access This article is licensed under a Creative Commons Attribution 4.0 International License, which permits use, sharing, adaptation, distribution and reproduction in any medium or format, as long as you give appropriate credit to the original author(s) and the source, provide a link to the Creative Commons licence, and indicate if changes were made. The images or other third party material in this article are included in the article's Creative Commons licence, unless indicated otherwise in a credit line to the material. If material is not included in the article's Creative Commons licence and your intended use is not permitted by statutory regulation or exceeds the permitted use, you will need to obtain permission directly from the copyright holder. To view a copy of this licence, visit http://creativecommons.org/licenses/by/4.0/.

\section{References}

1. Orem J, Mbidde EK, Lambert B, de Sanjose S, Weiderpass E (2007) Burkitt's lymphoma in Africa, a review of the epidemiology and etiology. Afr Health Sci 7(3):166-175. https://doi.org/ 10.5555/afhs.2007.7.3.166

2. Victora GD, Dominguez-Sola D, Holmes AB, Deroubaix S, Dalla-Favera R, Nussenzweig MC (2012) Identification of human germinal center light and dark zone cells and their relationship to human B-cell lymphomas. Blood 120(11):2240 2248. https://doi.org/10.1182/blood-2012-03-415380

3. Schmitz R, Ceribelli M, Pittaluga S, Wright G, Staudt LM (2014) Oncogenic mechanisms in Burkitt lymphoma. Cold Spring Harb Perspect Med. https://doi.org/10.1101/cshperspect.a014282

4. Neiman PE, Thomas SJ, Loring G (1991) Induction of apoptosis during normal and neoplastic B-cell development in the bursa of Fabricius. Proc Natl Acad Sci USA 88(13):5857-5861. https:// doi.org/10.1073/pnas.88.13.5857

5. Love C, Sun Z, Jima D, Li G, Zhang J, Miles R, Richards KL, Dunphy CH, Choi WW, Srivastava G, Lugar PL, Rizzieri DA, Lagoo AS, Bernal-Mizrachi L, Mann KP, Flowers CR, Naresh KN, Evens AM, Chadburn A, Gordon LI, Czader MB, Gill JI, Hsi ED, Greenough A, Moffitt AB, McKinney M, Banerjee A, Grubor V, Levy S, Dunson DB, Dave SS (2012) The genetic landscape of mutations in Burkitt lymphoma. Nat Genet 44(12):1321-1325. https://doi.org/10.1038/ng.2468

6. Mawson AR, Majumdar S (2017) Malaria, Epstein-Barr virus infection and the pathogenesis of Burkitt's lymphoma. Int J Cancer 141(9):1849-1855. https://doi.org/10.1002/ijc.30885

7. Young LS, Rickinson AB (2004) Epstein-Barr virus: 40 years on. Nat Rev Cancer 4(10):757-768. https://doi.org/10.1038/nrc1452

8. Cohen JI, Wang F, Mannick J, Kieff E (1989) Epstein-Barr virus nuclear protein 2 is a key determinant of lymphocyte transformation. Proc Natl Acad Sci USA 86(23):9558-9562. https://doi.org/ 10.1073/pnas.86.23.9558

9. Kerr BM, Lear AL, Rowe M, Croom-Carter D, Young LS, Rookes SM, Gallimore PH, Rickinson AB (1992) Three transcriptionally distinct forms of Epstein-Barr virus latency in somatic cell hybrids: cell phenotype dependence of virus promoter usage. Virology 187(1):189-201. https://doi.org/10.1016/0042-6822(92) 90307-b

10. Price AM, Luftig MA (2015) To be or not IIb: a multi-step process for Epstein-Barr virus latency establishment and consequences for B cell tumorigenesis. PLoS Pathog 11(3):e1004656. https://doi. org/10.1371/journal.ppat.1004656

11. Leen A, Meij P, Redchenko I, Middeldorp J, Bloemena E, Rickinson A, Blake N (2001) Differential immunogenicity of EpsteinBarr virus latent-cycle proteins for human CD4(+) T-helper 1 responses. J Virol 75(18):8649-8659. https://doi.org/10.1128/jvi. 75.18.8649-8659.2001

12. Hislop AD, Taylor GS, Sauce D, Rickinson AB (2007) Cellular responses to viral infection in humans: lessons from Epstein-Barr virus. Annu Rev Immunol 25:587-617. https://doi.org/10.1146/ annurev.immunol.25.022106.141553

13. Babcock GJ, Decker LL, Volk M, Thorley-Lawson DA (1998) EBV persistence in memory B cells in vivo. Immunity 9(3):395404. https://doi.org/10.1016/s1074-7613(00)80622-6

14. Mautner J, Pich D, Nimmerjahn F, Milosevic S, Adhikary D, Christoph H, Witter K, Bornkamm GW, Hammerschmidt W, Behrends U (2004) Epstein-Barr virus nuclear antigen 1 evades direct immune recognition by CD4+ T helper cells. Eur J Immunol 34(9):2500-2509. https://doi.org/10.1002/eji.200324794

15. Ramiro AR, Jankovic M, Eisenreich T, Difilippantonio S, ChenKiang S, Muramatsu M, Honjo T, Nussenzweig A, Nussenzweig MC (2004) AID is required for c-myc/IgH chromosome 
translocations in vivo. Cell 118(4):431-438. https://doi.org/10. 1016/j.cell.2004.08.006

16. Kalchschmidt JS, Bashford-Rogers R, Paschos K, Gillman AC, Styles CT, Kellam P, Allday MJ (2016) Epstein-Barr virus nuclear protein EBNA3C directly induces expression of AID and somatic mutations in B cells. J Exp Med 213(6):921-928. https://doi.org/ 10.1084/jem.20160120

17. Tanaka H, Matsumura I, Ezoe S, Satoh Y, Sakamaki T, Albanese C, Machii T, Pestell RG, Kanakura Y (2002) E2F1 and c-Myc potentiate apoptosis through inhibition of NF-kappaB activity that facilitates MnSOD-mediated ROS elimination. Mol Cell 9(5):1017-1029. https://doi.org/10.1016/s1097-2765(02)00522-1

18. Cahir-McFarland ED, Davidson DM, Schauer SL, Duong J, Kieff E (2000) NF-kappa B inhibition causes spontaneous apoptosis in Epstein-Barr virus-transformed lymphoblastoid cells. Proc Natl Acad Sci USA 97(11):6055-6060. https://doi.org/10.1073/pnas. 100119497

19. You Z, Madrid LV, Saims D, Sedivy J, Wang CY (2002) c-Myc sensitizes cells to tumor necrosis factor-mediated apoptosis by inhibiting nuclear factor kappa B transactivation. J Biol Chem 277(39):36671-36677. https://doi.org/10.1074/jbc.M203213200

20. Pajic A, Staege MS, Dudziak D, Schuhmacher M, Spitkovsky D, Eissner G, Brielmeier M, Polack A, Bornkamm GW (2001) Antagonistic effects of c-myc and Epstein-Barr virus latent genes on the phenotype of human B cells. Int J Cancer 93(6):810-816. https://doi.org/10.1002/ijc.1404

21. Faumont N, Durand-Panteix S, Schlee M, Grömminger S, Schuhmacher M, Hölzel M, Laux G, Mailhammer R, Rosenwald A, Staudt LM, Bornkamm GW, Feuillard J (2009) c-Myc and Rel/ NF-kappaB are the two master transcriptional systems activated in the latency III program of Epstein-Barr virus-immortalized B cells. J Virol 83(10):5014-5027. https://doi.org/10.1128/jvi. 02264-08

22. Müller JR, Janz S, Goedert JJ, Potter M, Rabkin CS (1995) Persistence of immunoglobulin heavy chain/c-myc recombinationpositive lymphocyte clones in the blood of human immunodeficiency virus-infected homosexual men. Proc Natl Acad Sci USA 92(14):6577-6581. https://doi.org/10.1073/pnas.92.14.6577

23. Roschke V, Kopantzev E, Dertzbaugh M, Rudikoff S (1997) Chromosomal translocations deregulating c-myc are associated with normal immune responses. Oncogene 14(25):3011-3016. https:// doi.org/10.1038/sj.onc.1201156

24. Pajic A, Polack A, Staege MS, Spitkovsky D, Baier B, Bornkamm GW, Laux G (2001) Elevated expression of c-myc in lymphoblastoid cells does not support an Epstein-Barr virus latency III-to-I switch. J Gen Virol 82(Pt 12):3051-3055. https://doi.org/10.1099/ 0022-1317-82-12-3051

25. Polack A, Hörtnagel K, Pajic A, Christoph B, Baier B, Falk M, Mautner J, Geltinger C, Bornkamm GW, Kempkes B (1996) c-myc activation renders proliferation of Epstein-Barr virus (EBV)-transformed cells independent of EBV nuclear antigen 2 and latent membrane protein 1. Proc Natl Acad Sci USA 93(19):10411-10416. https://doi.org/10.1073/pnas.93.19.10411

26. Long HM, Leese AM, Chagoury OL, Connerty SR, Quarcoopome J, Quinn LL, Shannon-Lowe C, Rickinson AB (2011) Cytotoxic CD4+ T cell responses to EBV contrast with CD8 responses in breadth of lytic cycle antigen choice and in lytic cycle recognition. J Immunol (Baltimore Md: 1950) 187(1):92-101. https://doi.org/ 10.4049/jimmunol.1100590

27. Merlo A, Turrini R, Bobisse S, Zamarchi R, Alaggio R, Dolcetti R, Mautner J, Zanovello P, Amadori A, Rosato A (2010) Virusspecific cytotoxic CD4+ T cells for the treatment of EBV-related tumors. J Immunol (Baltimore, Md: 1950) 184(10):5895-5902. https://doi.org/10.4049/jimmunol.0902850

28. Wilson AD, Redchenko I, Williams NA, Morgan AJ (1998) CD4+ $\mathrm{T}$ cells inhibit growth of Epstein-Barr virus-transformed $\mathrm{B}$ cells through CD95-CD95 ligand-mediated apoptosis. Int Immunol 10(8):1149-1157. https://doi.org/10.1093/intimm/10.8.1149

29. Svedmyr EA, Deinhardt F, Klein G (1974) Sensitivity of different target cells to the killing action of peripheral lymphocytes stimulated by autologous lymphoblastoid cell lines. Int J Cancer 13(6):891-903. https://doi.org/10.1002/ijc.2910130617

30. Vockerodt M, Yap LF, Shannon-Lowe C, Curley H, Wei W, Vrzalikova K, Murray PG (2015) The Epstein-Barr virus and the pathogenesis of lymphoma. J Pathol 235(2):312-322. https://doi. org/10.1002/path.4459

31. Guech-Ongey M, Simard EP, Anderson WF, Engels EA, Bhatia K, Devesa SS, Mbulaiteye SM (2010) AIDS-related Burkitt lymphoma in the United States: what do age and CD4 lymphocyte patterns tell us about etiology and/or biology? Blood 116(25):5600-5604. https://doi.org/10.1182/ blood-2010-03-275917

32. Nagy N, Adori M, Rasul A, Heuts F, Salamon D, Ujvári D, Madapura HS, Leveau B, Klein G, Klein E (2012) Soluble factors produced by activated CD4+ T cells modulate EBV latency. Proc Natl Acad Sci USA 109(5):1512-1517. https://doi.org/10. 1073/pnas.1120587109

33. Pokrovskaja K, Ehlin-Henriksson B, Kiss C, Challa A, Gordon J, Gogolak P, Klein G, Szekely L (2002) CD40 ligation downregulates EBNA-2 and LMP-1 expression in EBV-transformed lymphoblastoid cell lines. Int J Cancer 99(5):705-712. https:// doi.org/10.1002/ijc. 10417

34. Mordasini V, Ueda S, Aslandogmus R, Berger C, Gysin C, Hühn D, Sartori AA, Bernasconi M, Nadal D (2017) Activation of ATR-Chk1 pathway facilitates EBV-mediated transformation of primary tonsillar B-cells. Oncotarget 8(4):6461-6474. https:// doi.org/10.18632/oncotarget. 14120

35. Johannsen E, Luftig M, Chase MR, Weicksel S, CahirMcFarland E, Illanes D, Sarracino D, Kieff E (2004) Proteins of purified Epstein-Barr virus. Proc Natl Acad Sci USA 101(46):16286-16291. https://doi.org/10.1073/pnas.04073 20101

36. Tao Q, Robertson KD, Manns A, Hildesheim A, Ambinder RF (1998) The Epstein-Barr virus major latent promoter Qp is constitutively active, hypomethylated, and methylation sensitive. J Virol 72(9):7075-7083. https://doi.org/10.1128/jvi.72.9.70757083.1998

37. Chatterjee B, Deng Y, Holler A, Nunez N, Azzi T, Vanoaica LD, Müller A, Zdimerova H, Antsiferova O, Zbinden A, Capaul R, Dreyer JH, Nadal D, Becher B, Robinson MD, Stauss H, Münz C (2019) CD8 + T cells retain protective functions despite sustained inhibitory receptor expression during Epstein-Barr virus infection in vivo. PLoS Pathog 15(5):e1007748. https://doi.org/10.1371/ journal.ppat.1007748

38. Karachaliou N, Cao MG, Teixidó C, Viteri S, Morales-Espinosa D, Santarpia M, Rosell R (2015) Understanding the function and dysfunction of the immune system in lung cancer: the role of immune checkpoints. Cancer Biol Med 12(2):79-86. https://doi. org/10.7497/j.issn.2095-3941.2015.0029

39. Steff AM, Fortin M, Arguin C, Hugo P (2001) Detection of a decrease in green fluorescent protein fluorescence for the monitoring of cell death: an assay amenable to high-throughput screening technologies. Cytometry 45(4):237-243. https://doi.org/10.1002/ 1097-0320(20011201)45:4\%3c237::aid-cyto10024\%3e3.0.co;2-j

40. Farrell CJ, Lee JM, Shin EC, Cebrat M, Cole PA, Hayward SD (2004) Inhibition of Epstein-Barr virus-induced growth proliferation by a nuclear antigen EBNA2-TAT peptide. Proc Natl Acad Sci USA 101(13):4625-4630. https://doi.org/10.1073/pnas.03064 82101

41. Tagawa T, Albanese M, Bouvet M, Moosmann A, Mautner J, Heissmeyer V, Zielinski C, Lutter D, Hoser J, Hastreiter M, Hayes M, Sugden B, Hammerschmidt W (2016) Epstein-Barr 
viral miRNAs inhibit antiviral CD4+ T cell responses targeting IL-12 and peptide processing. J Exp Med 213(10):2065-2080. https://doi.org/10.1084/jem.20160248

42. God JM, Cameron C, Figueroa J, Amria S, Hossain A, Kempkes B, Bornkamm GW, Stuart RK, Blum JS, Haque A (2015) Elevation of c-MYC disrupts HLA Class II-mediated immune recognition of human B Cell tumors. J Immunol. https://doi.org/10.4049/ jimmunol.1402382

43. Kaiser C, Laux G, Eick D, Jochner N, Bornkamm GW, Kempkes B (1999) The proto-oncogene c-myc is a direct target gene of Epstein-Barr virus nuclear antigen 2. J Virol 73(5):4481-4484. https://doi.org/10.1128/JVI.73.5.4481-4484.1999

44. Jochner N, Eick D, Zimber-Strobl U, Pawlita M, Bornkamm GW, Kempkes B (1996) Epstein-Barr virus nuclear antigen 2 is a transcriptional suppressor of the immunoglobulin mu gene: implications for the expression of the translocated c-myc gene in Burkitt's lymphoma cells. EMBO J 15(2):375-382. https://doi. org/10.1002/j.1460-2075.1996.tb00367.x

45. Thomas LR, Tansey WP (2011) Proteolytic control of the oncoprotein transcription factor Myc. In: Klein G (ed) Advances in cancer research, vol 110. Academic Press, pp 77-106. https://doi. org/10.1016/B978-0-12-386469-7.00004-9

Publisher's Note Springer Nature remains neutral with regard to jurisdictional claims in published maps and institutional affiliations. 